PRIFYSGOL

glyndŵn

Glyndŵr University

Glyndŵr University Research Online

Mechanical Engineering

1-1-2009

\title{
Semi-Active Suspension System Simulation Using SIMULINK
}

S Abramov

S Mannan

samjid.mannan@kcl.ac.uk

Olivier Durieux

o.durieux@glyndwr.ac.uk

Follow this and additional works at: http://epubs.glyndwr.ac.uk/eng

Part of the Engineering Commons

Copyright (C) 2004-2010 Inderscience Enterprises Limited. All rights reserved. This is the author's post print version of an article published in the International Journal of Engineering Systems

Modelling and Simulation in 2009. The original publication is available at

http://www.inderscience.com

\section{Recommended Citation}

Abramov, S., Mannan, S., \& Durieux, O. (2009)'Semi-Active Suspension System Simulation Using SIMULINK'. International Journal of Engineering Systems Modelling and Simulation, 1(2/3), $101-114$

This Article is brought to you for free and open access by Glyndŵr University Research Online. It has been accepted for inclusion in Mechanical Engineering by an authorized administrator of Glyndŵr University Research Online. For more information, please contact d.jepson@glyndwr.ac.uk. 


\title{
Semi-Active Suspension System Simulation Using SIMULINK
}

\author{
Sergey Abramov ${ }^{1}$, Samjid Mannan $^{1}$ and Olivier Durieux ${ }^{2}$ \\ ${ }^{1}$ Department of Mechanical Engineering, Division of Engineering, School of Physical Sciences and \\ Engineering, King's College London, London, WC2R 2LS, UK \\ ${ }^{2}$ School of Science and Technology, Glyndwr University, Plas Coch, Mold Road, Wrexham, \\ LL11 2AW, UK, Corresponding Author, E-mail: o.durieux@glyndwr.ac.uk
}

\begin{abstract}
This paper describes a simulation design procedure aimed to achieve improved performance of the vehicle semi-active suspension. The issues related to the design of vehicle models with skyhook control are discussed. Three basic models with linear parameters are explained: quarter-, half- and full-car. The road profile is generated from a spatial power spectral density (PSD) to represent a typical road (based on ISO 8608 classification). The normalized root-mean-square values of sprung mass acceleration and tyre load forces are used to assess the vehicle ride comfort and handling performance based on five benchmark road profiles employed in industrial tests.
\end{abstract}

Key words: active suspension, semi-active suspension, full-car model, road profile, simulation, ride comfort, handling performance.

\section{Introduction}

Demands for better ride comfort, road handling and controllability of passenger cars have motivated automotive industries to use active and semi-active suspensions in middle-top range vehicles due to their effectiveness in order to increase the car comfort and stability.

Suppression of vibration in passive suspensions depends on the spring stiffness, damping coefficient, and car mass. Due to the fact that they cannot satisfy the comfort requirement under different road conditions, significant interest is being devoted to the control of active and semiactive suspension in both academia and industry.

Many analytical and experimental studies on active and semi-active suspensions have been performed to improve ride quality and handling performance. The results of studies show that active and semi-active suspensions can provide substantial performance improvements over passive suspensions in general (Williams, 1997).

The design of controlled suspension systems for road vehicles aims to optimize the performance of the vehicle with regard to comfort and road handling. Vehicle suspensions should serve several conflicting purposes. In addition to counteracting the body forces resulting from cornering, acceleration or braking and changes in payload, suspensions must isolate the passenger compartment from road irregularities. For driving safety, a permanent contact between the tyres and the road should be assured. Passive suspension systems built of springs and dampers have serious limitations. Their parameters have to be chosen to achieve a certain level of compromise between road holding, load carrying and comfort, under wide variety of road conditions.

Specific vehicle models need to be used in order to analyse the effectiveness of the active suspension system on vehicle dynamics. Passenger cars are complex multibody systems consisting of many rigid and deformable components. A full vehicle model needs to present the nonlinear kinematics of wheels and axles, the effects of suspension geometry and has to include the drive train, the steering mechanism and the tyre dynamics, resulting in a high number of degrees of freedom. Since it makes no sense to try to build a universal vehicle model that can be used to solve all dynamic problems, reduced dynamic models for specific investigation purposes are often designed instead (Gillespie, 1992). 
The application of active and semi-active suspensions involves the application of control algorithms. Active control concepts have been investigated extensively over the past decades (Appleyard and Wellstead, 1995; Kim et al., 2002; Fischer and Isermann, 2004). The purpose of an optimal control problem is to determine the control policy optimizing specific criteria, subject to the constraints imposed by the physical nature of the problem.

The well known suspension oriented skyhook control algorithm, widely explored in the literature, (Sammier et al., 2003 and Emura et al., 1994) is addressed to the design of semi-active suspension. The peculiarity of this control algorithm is that the chassis is "linked" to the sky in order to reduce vertical oscillations of the chassis and of the axle independently of each other.

\section{Vehicle models}

There exist many possibilities arraying for describing the car suspension behaviour (quartercar model, half-car model and full-car model). There is an extensive amount of literature relating to these models (Croizet and Gatignol, 2002). The full-car model is presented in the following section.

The full-vehicle suspension system is represented as a linear seven degree-of-freedom (DOF) system. It consists of a single sprung mass (car body) connected to four unsprung masses (front-left, front-right, rear-left and rear-right wheels) at each corner. The sprung mass is free to bounce, pitch and roll while the unsprung masses are free only to bounce vertically with respect to the sprung mass. All other motions are neglected for this model. Hence this system has seven degrees of freedom and allows simulation of tyre load forces in all four tyres, body acceleration and vertical body displacement as well as roll and pitch motion of the car body. The suspensions between the sprung mass and unsprung masses are modelled as linear viscous dampers and linear spring elements, while the tyres are modelled as simple linear springs without damping. For simplicity, all pitch and roll angles are assumed to be small.

The model of a full-car suspension system is shown in Figure 1. The full-vehicle suspension model is represented as a linear seven degree of freedom system. The lateral dynamics of the vehicle are ignored. It consists of a single sprung mass $m$ (car body) connected to four unsprung masses $m_{1} \ldots m_{4}$ (front-left, front-right, rear-left and rear-right wheels) at each corner. The suspensions between the sprung mass and unsprung masses are modelled as linear viscous dampers and spring elements, while the tyres are modelled as simple linear springs without damping components (exactly in a same way as with quarter-car and half-car models). The actuator systems between the sprung body and the wheels provide forces determined by the displacement of the actuators. The dampers between the body and the wheels represent sources of conventional damping such as friction between the mechanical elements. For the vehicle modelling full-car will be used as a good approximation of the entire car. The equations of motion for this system are: 


$$
\left\{\begin{array}{l}
m_{1} \ddot{z}_{1}=k_{11}\left(q_{1}-z_{1}\right)+k_{12}\left(z_{1}^{\prime}-z_{1}\right)+c_{1}\left(\dot{z}_{1}^{\prime}-\dot{z}_{1}\right)+f_{d 1}+F_{r 1}+m_{1} g \\
m_{2} \ddot{z}_{2}=k_{21}\left(q_{2}-z_{2}\right)+k_{22}\left(z_{2}^{\prime}-z_{2}\right)+c_{2}\left(\dot{z}_{2}^{\prime}-\dot{z}_{2}\right)+f_{d 2}+F_{r 2}+m_{2} g \\
m_{3} \ddot{z}_{3}=k_{31}\left(q_{3}-z_{3}\right)+k_{32}\left(z_{3}^{\prime}-z_{3}\right)+c_{3}\left(\dot{z}_{3}^{\prime}-\dot{z}\right)_{3}+f_{d 3}+F_{r 3}+m_{3} g \\
m_{4} \ddot{z}_{4}=k_{41}\left(q_{4}-z_{4}\right)+k_{42}\left(z_{4}^{\prime}-z_{4}\right)+c_{4}\left(\dot{z}_{4}^{\prime}-\dot{z}_{4}\right)+f_{d 4}+F_{r 4}+m_{4} g \\
m_{\ddot{z}}=k_{12}\left(z_{1}-z_{1}^{\prime}\right)+k_{22}\left(z_{2}-z_{2}^{\prime}\right)+k_{32}\left(z_{3}-z_{3}^{\prime}\right)+k_{42}\left(z_{4}-z_{4}^{\prime}\right)+c_{1}\left(\dot{z}_{1}-\dot{z}_{1}^{\prime}\right)+c_{2}\left(\dot{z}_{2}-\dot{z}_{2}^{\prime}\right)+ \\
\quad+c_{3}\left(\dot{z}_{3}-\dot{z}_{3}^{\prime}\right)+c_{4}\left(\dot{z}_{4}-\dot{z}_{4}^{\prime}\right)-f_{d 1}-f_{d 2}-f_{d 3}-f_{d 4}-F_{r 1}-F_{r 2}-F_{r 3}-F_{r 4}+m g \\
J_{X} \ddot{\varphi}=-\left[k_{32}\left(z_{3}-z_{3}^{\prime}\right)+c_{3}\left(\dot{z}_{3}-\dot{z}_{3}^{\prime}\right)+k_{42}\left(z_{4}-z_{4}^{\prime}\right)+c_{4}\left(\dot{z}_{4}-\dot{z}_{4}^{\prime}\right)\right] c+ \\
\quad+\left[k_{12}\left(z_{1}-z_{1}^{\prime}\right)+c_{1}\left(\dot{z}_{1}-\dot{z}_{1}^{\prime}\right)+k_{22}\left(z_{2}-z_{2}^{\prime}\right)+c_{2}\left(\dot{z}_{2}-\dot{z}_{2}^{\prime}\right)\right] d+ \\
\quad+\left(f_{d 1}+f_{d 2}\right) d-\left(f_{d 3}+f_{d 4}\right) c-\left(F_{r 1}+F_{r 2}\right) d+\left(F_{r 3}+F_{r 4}\right) c \\
J_{Y} \ddot{\theta}=-\left[k_{12}\left(z_{1}-z_{1}^{\prime}\right)+c_{1}\left(\dot{z}_{1}-\dot{z}_{1}^{\prime}\right)+k_{42}\left(z_{4}-z_{4}^{\prime}\right)+c_{4}\left(\dot{z}_{4}-\dot{z}_{4}^{\prime}\right)\right] a+ \\
\quad+\left[k_{22}\left(z_{2}-z_{2}^{\prime}\right)+c_{2}\left(\dot{z}_{2}-\dot{z}_{2}^{\prime}\right)+k_{32}\left(z_{3}-z_{3}^{\prime}\right)+c_{3}\left(\dot{z}_{3}-z_{3}^{\prime}\right)\right] c+ \\
\quad+\left(f_{d 2}+f_{d 3}\right) b-\left(f_{d 1}+f_{d 4}\right) a-\left(F_{r 2}+F_{r 3}\right) b+\left(F_{r 1}+F_{r 4}\right) a .
\end{array}\right.
$$

where $m_{1} \ldots m_{4}$ are the wheel masses (unsprung); $m$ is the chassis mass(sprung); $k_{11} \ldots k_{41}$ are the tyre stiffness coefficients; $k_{12} \ldots k_{42}$ are the suspension stiffness coefficients; $c_{1} \ldots c_{4}$ are the damping coefficients; $a, b, c$ and $d$ are the distances of the chassis barycentre from suspensions; $q_{1} \ldots q_{4}$ are the road profiles; $z_{1} \ldots z_{4}$ are the wheel vertical positions; $z_{1}^{\prime} \ldots z_{4}^{\prime}$ are the chassis vertical positions; $z$ is the chassis barycentre vertical position; $J_{X}$ is the chassis moment of inertia around $\mathrm{X}$ axis; $J_{Y}$ is the chassis moment of inertia around $\mathrm{Y}$ axis; $\varphi$ is the chassis roll angle in radians; $\theta$ is the chassis pitch angle in radians; $F_{r 1} \ldots F_{r 4}$ are the frictional forces due to rubbing of pistons seals with the cylinder walls inside the actuators; $f_{d 1} \ldots f_{d 4}$ are the hydraulic forces provided by actuators, they are positive when the actuators are under compression.

\section{Road profiles}

As with any random signal, the elevation profile measured over a length of road can be decomposed by a Fourier transformation into a series of sine waves varying in their amplitudes and phase relationships. A plot of the amplitudes against spatial frequency can be represented as PSD. Spatial frequency is expressed as the wave-number with units of cycles/meter and is the inverse of the wavelength of the sine wave on which it is based. From experimental measurements of the road profile a law $h(x)$ can be defined and its power spectral density can be obtained through harmonic analysis. Note that the profile is a function of space and not of time and the frequency referred to space $\bar{\lambda}$ is expressed in $\mathrm{rad} / \mathrm{m}$ or cycles/m and not in $\mathrm{rad} / \mathrm{s}$ or $\mathrm{Hz}$. The power spectral density $\bar{S}$ of law $h(x)$ is thus expressed in $\mathrm{m}^{2} /(\mathrm{rad} / \mathrm{m})$ or in $\mathrm{m}^{2} /($ cycles $/ \mathrm{m})$.

A real road surface is taken as a random exciting function, which is used as input to the vehicle road model. It is noted that the main characteristic of a random function is uncertainty. That is, there is no method to predict an exact value at a future time. The function should be described in terms of probability statements as statistical averages, rather than explicit equations. In road models, power spectral density has been used to describe the basic properties of random data.

The International Organization for Standardization (ISO) introduced the road roughness classification (classes A-H) which is based on the power spectral density (PSD) values. Random road profiles can be approximated by a PSD in the form of:

$$
\Phi(\Omega)=\Phi\left(\Omega_{0}\right)\left[\frac{\Omega}{\Omega_{0}}\right]^{-\omega}
$$

where $\Omega=2 \pi / \mathrm{L}$ in $\mathrm{rad} / \mathrm{m}$ denotes the wave number and $\Phi_{0}=\Phi\left(\Omega_{0}\right)$ in $\mathrm{m}^{2} /(\mathrm{rad} / \mathrm{m})$, the road roughness coefficient, describes the value of the PSD at a the reference wave number $\Omega_{0}=1 \mathrm{rad} / \mathrm{m}$. 
The drop in magnitude is modelled by the waviness $\omega$. By setting the waviness to $\omega=2$ each class is simply defined by its reference value $\Phi_{0}$. Class A with $\Phi_{0}=4 \cdot 10^{-6} \mathrm{~m}^{2} /(\mathrm{rad} / \mathrm{m})$ characterizes very smooth highways, whereas class $E$ with $\Phi_{0}=256 \cdot 10^{-6} \mathrm{~m}^{2} /(\mathrm{rad} / \mathrm{m})$ represents rather rough roads.

ISO standards suggest $\omega=2$ for road undulations, i.e. for disturbances with a wavelength greater than 6 meters, and $\omega=1.37$ for irregularities with a wavelength smaller than 6 meters.

If the vehicle travels with velocity $V$ it is possible to transform the law $h(x)$ into a law $h(t)$ and compute the frequency $\lambda$ and a power spectral density $S$ (measured in $\mathrm{m}^{2} /\left(\mathrm{rad} / \mathrm{s}\right.$ ) or $\mathrm{m}^{2} / \mathrm{Hz}$ ) referred to time from $\bar{\lambda}$ and $\bar{S}$ defined with respect to space.

$$
\begin{aligned}
\lambda & =V \bar{\lambda} \\
S & =\frac{\bar{S}}{V}
\end{aligned}
$$

A random profile of a single track can be approximated by a superposition of $N \rightarrow \infty$ sine waves:

$$
z_{R}(s)=\sum_{i=1}^{N} A_{i} \sin \left(\Omega_{i} s-\psi_{i}\right)
$$

where each sine wave is determined by its amplitude $A_{i}=\sqrt{2 \Phi\left(\Omega_{i}\right) \Delta \Omega}(i=1 \ldots N)$ and its wave number $\Omega_{i}$ (4). By different sets of uniformly distributed phase angles $\psi_{i}(i=1 \ldots N)$ in the range between 0 and $2 \pi$ different profiles can be generated which are similar in the general appearance but different in details.

\section{Skyhook control}

One of the most popular and implemented controllers for the semi-active suspensions in commercial applications is the skyhook damping concept. In the skyhook damping process a damper is placed between the sprung mass and an imaginary point in the sky. This is equivalent to the negative feedback of the sprung mass velocity with appropriate amplification such that there is no force applied to the unsprung mass (the wheel and tyre assembly). Such a scheme is shown to be very effective in controlling the sprung mass acceleration and is attractive because of its inherent simplicity from a practical point of view.

The key issue with the skyhook approach is that it is not practically implementable, because finding an imaginary point in the sky for fixing the damper is not possible. The practical implementation calls for the use of an actuator between the sprung and the unsprung masses, see Figure 2. However, this leads to deterioration of the unsprung mass dynamic performance as the controller force input has to be applied on both the sprung as well as the unsprung masses. Thus the dynamic response of the practical skyhook damping system is considerably worse than that of the ideal skyhook-based suspension system.

\subsection{On-off skyhook control}

The philosophy of the on-off skyhook control method is to emulate the effect of a passive damper "hooked" between the body mass and the "sky", as shown in Figure 3. In this two-state skyhook control, the damper is adjusted to a maximum or minimum damping. These are referred to as high-state and low state damping, respectively. The determination of whether the damper is to be adjusted to either its high state or its low state depends on the product of the relative speed of the suspension damper and the absolute speed of the sprung mass attached to that damper. If the product is positive or zero, the damper is adjusted to its high state; otherwise, the damper is set to the low state. This concept is summarized by: 


$$
u= \begin{cases}u_{\max }, & \text { if } \quad \dot{z}_{2}\left(\dot{z}_{2}-\dot{z}_{1}\right) \geq 0 \\ u_{\min }, & \text { if } \quad \dot{z}_{2}\left(\dot{z}_{2}-\dot{z}_{1}\right)<0\end{cases}
$$

This two-state skyhook semi-active policy emulates the ideal body displacement control configuration of a passive damper hooked between the sprung mass and the sky, as explained in greater detail in the next section.

\subsection{Continuous skyhook control}

In continuous damping, there exists a high state and a low state of damping as in the on-off damping control policy described previously. In continuous control, however, the damping values are not limited to these two states alone; they may exist at any value within the two states. The high and low states serve as the maximum and minimum damping values, respectively, with the intermediate area as all possible damping values between the maximum and minimum. An extension of the on-off skyhook control policy was used as one method of continuous control. As in on-off skyhook control, equations (5) still apply, except for the definition of the high-state and lowstate damping. In on-off skyhook control, the high and low states were defined as constant damping values. In continuous skyhook control, the low state remains defined by a constant damping value, while the high state is set equal to a constant gain value multiplied by the absolute velocity of the vehicle body attached to the damper, not to exceed the corresponding high and low state limits.

\subsection{Semi-active realization of skyhook control}

Once the semi-active damper is chosen for the implementation, one must determine how to modulate the damper such that it emulates a skyhook damper. First the velocity of the sprung mass relative to the unsprung mass, $\left(\dot{z}_{2}-\dot{z}_{1}\right)$, should be defined to be positive when the base and mass are separating (i.e., when $\dot{z}_{2}$ is greater than $\dot{z}_{1}$ ). Now assume that the sprung mass is moving upwards with a positive velocity $\dot{z}_{2}$. The force that would be applied by a skyhook damper to the sprung mass, one could notice that is negative:

$$
F_{\text {sky }}=-c_{\text {sky }} \dot{z}_{2}
$$

where $F_{\text {sky }}$ is the skyhook force.

Next, one needs to determine if the semi-active damper is able to provide the same force. If the unsprung and sprung masses in Figure 3 are separating, then the semi-active damper is in tension. Thus, the force applied to the sprung mass is in the negative $z_{2}$ direction:

$$
F_{\text {contr }}=-c_{\text {contr }}\left(\dot{z}_{2}-\dot{z}_{1}\right)
$$

where $F_{\text {contr }}$ is the force applied to the sprung mass.

Since the actuator is able to generate a force in the proper direction, the only requirement to match the skyhook suspension is:

$$
c_{\text {contr }}=\frac{c_{\text {sky }} \dot{z}_{2}}{\left(\dot{z}_{2}-\dot{z}_{1}\right)}
$$

To summarize, if $\dot{z}_{2}$ and $\left(\dot{z}_{2}-\dot{z}_{1}\right)$ are positive, $c_{\text {contr }}$ should be defined as in equation (8).

Now consider the case in which the unsprung and sprung masses are still separating, but the sprung mass is moving downwards with a negative velocity $\dot{z}_{2}$. In the skyhook configuration, the damping force will now be applied in the upwards, or positive, $z_{2}$ direction. In the semi-active configuration, however, the semi-active damper is still in tension, and the damping force will still be applied in the downwards, or negative, direction. Since the semi-active damping force cannot possibly be applied in the same direction as the skyhook damping force, the best that can be achieved is to minimize the damping force. Ideally, the semi-active damper is desired to be set so that there is no damping force, but in reality there is some small damping force present and it is not 
in the same direction as the skyhook damping force. Thus, if $\left(\dot{z}_{2}-\dot{z}_{1}\right)$ is positive and $\dot{z}_{2}$ is negative, one needs to minimize the semi-active damping force. The same simple analysis can be applied to the other two combinations of $\dot{z}_{2}$ and $\left(\dot{z}_{2}-\dot{z}_{1}\right)$, resulting in the well-known semi-active skyhook control policy. This equation implies that when the relative velocity across the suspension and sprung mass $\left(\dot{z}_{2}-\dot{z}_{1}\right)$ have the same sign, a damping force proportional to $\dot{z}_{2}$ is desired. Otherwise, the minimal amount of damping is desired. Further, this equation provides a very simple method to emulate the ideal skyhook suspension system using only a semi-active damper.

\section{Implementation and results}

\subsection{Simulation and performance evaluation settings}

In order to investigate, in a realistic fashion, the performance of the practical skyhook controller, the vehicle models implemented in MATLAB (Figures 4 and 5) are used. These models provide simulation results of a vehicle equipped with continuous damping control. Such simulations have been carried out using the following benchmark road profiles employed in industrial tests:

1. Random profiles belonging to ISO A, B and C classes run at 60,90 , and $120 \mathrm{~km} / \mathrm{h}$;

2. Sine wave hole test (SWT) with maximum amplitude of $0.03 \mathrm{~m}$ and width of $6 \mathrm{~m}$ run at 60 , 90 , and $120 \mathrm{~km} / \mathrm{h}$;

3. Short back test (SBT): a positive road impulse with amplitude of $0.02 \mathrm{~m}$ and width of $0.5 \mathrm{~m}$ run at 60,90 , and $120 \mathrm{~km} / \mathrm{h}$;

4. Drain well test (DWT): a negative road impulse with amplitude of $0.05 \mathrm{~m}$ and width of $0.6 \mathrm{~m}$ run at 60,90 , and $120 \mathrm{~km} / \mathrm{h}$;

5. English track test (ETT): a very demanding road profile with irregularly spaced sequences of bumps and holes with maximum amplitude of $0.02 \mathrm{~m}$ and width of 0.5 to $1 \mathrm{~m}$ run at 60 , 90 , and $120 \mathrm{~km} / \mathrm{h}$ as well.

\subsection{Ride comfort performance evaluation}

Ride comfort is the general sensation of noise, vibration and motion inside a driven vehicle, experienced by both the driver as well as the passengers. Ride comfort optimization affects the comfort, safety and health of the passengers subjected to it:

- comfort: the first impression during a drive is an important criterion and therefore represents the first appreciation of the vehicle;

- safety: reduced concentration for the driver of a noisy vehicle after several hours on the road results in the high risk of accidents;

- health: long term exposure to vibrations can cause lower back pain problems for the driver of trucks, buses or heavy off-road vehicles.

The quality referred to as ride comfort is affected by a variety of factors, including high frequency vibrations, body booming, body roll and pitch, as well as the vertical spring action normally associated with a smooth ride. If the vehicle is noisy, if it rolls excessively in turns, or pitches during acceleration and braking, or if the body produces a booming resonance, passengers will experience an uncomfortable ride.

The ride quality, normally associated with the vehicle's response to bumps, is a factor of the relatively low frequency bounce and rebound movements of the suspension system. Following a bump, the undamped suspension (without shocks) of a vehicle will experience a series of oscillations that will cycle according to the natural frequency of the system. Ride is perceived as most comfortable when the natural frequency is in the range of 60 to 90 cycles per minute (CPM), or about $1 \mathrm{~Hz}$ to $1.5 \mathrm{~Hz}$. When the frequency approaches $120 \mathrm{CPM}(2 \mathrm{~Hz})$, passengers perceive the ride as harsh. 
Ride comfort deteriorates when the road roughness coefficient is increased (ISO classification of road roughness). The reason for this is the rolling resistance coefficient, which is not a constant but varies with the road roughness coefficient and the vehicle speed. Hence, when the road roughness coefficient is increased, the rolling resistance force induced by road roughness increases too.

Measuring and quantifying ride comfort can help development teams in meeting the necessary standards and regulations, but moreover gives the required insight to troubleshoot, understand and improve the noise and vibration comfort of the vehicle.

In order to give a quantitative evaluation of the ride comfort performances achieved by the considered control strategy, the RMS value of the sprung mass acceleration $\ddot{z}_{s}$, normalized with respect to the gravity acceleration $g$ can be considered:

$$
z_{s, R M S}=\sqrt{\frac{1}{\tau} \int_{t=0}^{\tau}\left[\frac{\ddot{z}_{s}(t)}{g}\right] d t}
$$

\subsection{Handling performance evaluation}

The handling characteristics of an automobile are concentrated on the characteristics of the tyres. Tyres are the vehicle's reaction point with the roadway. They manage the input of forces and disturbances from the road, and they are the final link in the driver's chain of output commands. Tyre characteristics are therefore a key factor in the effect the road has on the vehicle, and in the effectiveness of the output forces that control vehicle stability and cornering characteristics. The tyre's basic characteristics are managed by the system of springs, dampers, and linkages that control the way in which tyres move and react to disturbances and control inputs.

Tyres play a significant part in vehicle handling characteristics. Low profile sidewalls improve steering response but also stiffen the ride, so for optimum handling, the tyres, springs and shock absorbers must all work together as a package.

For example, rollover of vehicles is one of the major causes of highway accidents. Rollover generally occurs when a vehicle is subjected to extreme steering and braking inputs. To prevent rollover, there is a need to optimize those vehicle and suspension parameters that will make the design less susceptible to rollover.

Increasing safety requirements on the handling performance of vehicles demand tools, which allow predicting the tyre influences on the vehicle dynamics. Computer simulation of handling performance of vehicles facilitates evaluation of the influence of tyre design changes on handling properties.

The vehicle motions are caused primarily by tyre forces and moments that result from power train, braking, and steering inputs. Tyre forces represent a significant part of the vehicle dynamic behaviour. A comprehensive tyre model is therefore of considerable importance.

In summary the handling performance of the vehicle depends on the forces that are exchanged between tyre and road. For a quarter-car model, for example, this force is given by the equation: $F_{z 1}=k_{1}\left(z_{1}-q\right)$. Then the RMS values of these forces, normalized with respect to the static forces acting on the wheels (if gravity is taken into account in the considered system) $F_{z u}^{\text {start }}=\left(m_{1}+m_{2}\right) g$, can be used to evaluate the handling performance:

$$
F_{z u, R M S}=\sqrt{\frac{1}{\tau} \int_{t=0}^{\tau}\left[\frac{F_{z u}(t)}{F_{z u}^{\text {start }}}\right] d t}
$$

\subsection{Random profiles test}

This kind of road profile is widely used to test vehicle basic comfort and handling performances. Different road roughness characteristics have been taken into account according to 
the ISO classification (Hrovat, 1997). In particular, profiles belonging to ISO classes A (very good), B (good), and C (average), have been employed at different speeds, namely 60, 90, and $120 \mathrm{~km} / \mathrm{h}$.

To illustrate this, the comfort and handling performance results obtained for quarter- and full-car models subjected to ISO B random profile are summarized in Figures. 6 and 7, respectively.

In regards to the handling performances for the full-car model, only the front left tyre force results are reported. Similar behaviours have been obtained for the rear suspension.

The objective of the system analysis in the random profile test is to estimate the performance of the skyhook controller applied to quarter-car and full-car systems. This performance is evaluated based on the normalized RMS values of the sprung mass bounce acceleration ( $1^{\text {st }}$ stage of the test) and tyre load force ( $2^{\text {nd }}$ stage of the test).

These values for the passive and semi-active systems are compared to each other at different vehicle speeds. Hence it is possible to plot piece-wise linear curves, combining together six RMS values (two values for each speed). The easiest way to obtain these results quickly is to have three identical models, subjected to three different inputs. These inputs correspond to three speeds $(60,90$ and $120 \mathrm{~km} / \mathrm{h}$ ). In this case the outputs are the sprung mass accelerations for passive and semiactive systems for three different speeds (six vectors of data). Then the RMS values of these 6 vectors are calculated and two piece-wise linear curves are plotted. After the quarter-car model tests, the experiment is repeated for the full-car, travelling the ISO class A profile. Then the same procedure is applied for the ISO class B and C profiles. The results for each class of road roughness are then combined together. Since the resulting model for this experiment is very large, it is not represented here. The analysis of the results reported for the skyhook strategy, for example, for ISO class B profile (Figures 6 and 7), shows that the enhancements on comfort index (9) ranges from the $18 \%$ to the $34 \%$ with respect to the passive system. As for the handling performance evaluated according to the index (10), one should say that it has reduced significantly (but remaining within a $10 \%$ range) due to the tyre-load force decrease.

\subsection{Sine wave hole test}

Sine wave holes present a rigorous test of the performance of vehicle suspension systems. In particular, as the length of the hole is greater than the distance between front and rear axles, pitch motions are effectively excited (Gillespie, 1992). Moreover, given the amplitude characteristics of such road holes, bounce performances can be evaluated as well. In order to perform an extensive test on such road profile vehicle speeds of 60,90 and $120 \mathrm{~km} / \mathrm{h}$ have been considered. The achieved comfort and handling performance computed according to the indexes (9) and (10) are presented in Figures 8-11. It is evident that the use of the skyhook strategy ensure higher comfort performance levels with respect to the passive system, for both quarter-car and full-car models. Pitch performances can be evaluated by means of the RMS value of the pitch acceleration $\theta(t)$ :

$$
\ddot{\theta}_{R M S}=\sqrt{\frac{1}{\tau} \int_{t=0}^{\tau}[\ddot{\theta}(t)]^{2} d t}
$$

Bounce behaviour of the controlled vehicle can be taken into account by means of the sprung mass acceleration response in the opposite direction to the hole. A suitable measure to evaluate such performance is the positive peak value of the sprung mass acceleration

$$
\ddot{z}_{\max }=\max _{t} \ddot{z}(t)
$$

A resume of the bounce performances is shown in Figures 8-10. It can be observed that similar improvements of the comfort index are obtained by the skyhook control at every vehicle speed. These results illustrate significant enhancement of the system performance. Contrary to these enhancements, the road handling performance is reduced as in the previous set of tests (Figure 11).

5.6 Short back, drain well and English track tests 
This set of road profiles is used to test suspension performances in the presence of impulsive road irregularities.

Due to the impulsive nature of short back and drain well profiles, an analysis of bounce performances should be carried out. As seen for the sine wave hole test, sprung mass acceleration response in the opposite direction of the bump can be taken as a suitable parameter. In particular, for the short back profile, the negative peak of the sprung mass acceleration defined as:

$$
\ddot{z}_{\min }=\min _{t} \ddot{z}(t)
$$

can be considered, while for the drain well profile the index (12) is employed.

The simulation results related to ride comfort and handling measures (9) and (10), obtained for the short back, drain well and English track tests are presented in Figures 12-17. It can be noted that an improvement between $14 \%$ and $20 \%$ is obtained for the comfort index with respect to passive system for all the three road profiles. The tyre-load force in the short back test demonstrates reduction as in both previous tests. However, for the drain well and English track tests this decrease is negligible.

\section{Conclusion}

The research presented in this paper is directed to the simulation and design of a semi-active suspension. Although based on the well-known physical models for investigating the vertical dynamics of suspension systems (Hrovat, 1997; Kruczek and Stribrsky, 2004), it is expanded with an extensive set of simulations based on SIMULINK modelling and benchmark road profiles employed in real industrial tests (such as sine wave hole test, short back, drain well, etc.). More accurate analysis is achieved by extension to a full-car model, which is subjected to the benchmark tests. The skyhook control strategy is evaluated by means of multiple criteria, i.e., the comfort and handling are defined by equations (9) and (10), respectively, for all the classes of road profiles. Moreover, additional comfort criteria are evaluated for some of the profiles.

For example, in regards to the bounce results obtained in the simulations, skyhook control shows good improvements over passive system performance for the random profile and sine wave hole test. The use of this kind of road profile allows a deeper analysis on how the skyhook controller works in order to achieve such performance enhancements.

In addition, it can be seen that skyhook control improves, in a significant way, comfort characteristics in comparison with the passive system in a short back, drain well and English track tests. However, contrary to what happens for the comfort index, handling performances, obtained with skyhook control, exhibit a degradation with respect to the passive system for the random, sine wave and short back road profiles (typically within a range of 10\%). For the last two tests this degradation is negligible.

The main conclusions that may be derived from this research are the following:

1. A control approach based on skyhook algorithm for semi-active suspension systems has been implemented in the SIMULINK environment. In order to show the effectiveness of the proposed procedure, performance comparison with passive system has been presented.

2. Extensive simulation tests have been performed on the quarter-car and full-car linear models, which provide an accurate enough description of the dynamic behaviour of a vehicle equipped with continuous damping control.

3. On the basis of such results, it can be concluded that the inclusion of the skyhook algorithm in a semi-active control system improves the comfort index of semi-active suspensions systems by $14 \% . .34 \%$, keeping the handling performance within the acceptable range of $10 \%$ degradation. 


\section{References}

Appleyard, M. and Wellstead, P. E. (1995) Active suspension: some background, IEE Proceedings on Control Theory and Applications, Vol. 142, No 2, pp. 123-128.

Croizet, C. and Gatignol, R. (2002) Boltzmann-like modelling of a suspension, Math. Mod. Meth. Appl.Sci., Vol. 12, pp. 943-964.

Emura, J., Kakizaki, S., Yamaoka, F. and Nakamura M. (1994) Development of the semi-active suspension system based on the skyhook damper theory, SAE Paper, No 940863.

Fischer D. and Isermann R. (2004) Mechatronic semi-active and active vehicle suspensions, Control Engineering Practice, Vol. 12, No 11, pp. 1353-1367.

Gillespie, T. D. (1992) Fundamentals of vehicle dynamics, Society of Automotive Engineers, Warrendale, PA, 495p.

Hrovat, D. (1997) Survey of advanced suspension development and related optimal control applications, Automatica, Vol. 33, No 10, pp. 1781-1817.

Kim, H.-J., Yang, H. S. and Park, Y.-P. (2002) Improving the vehicle performance with active suspension using road-sensing algorithm, Computers and Structures, Vol. 80, No 18-19, pp. $1569-1577$

Kruczek, A. and Stribrsky, A. (2004) A full-car model for active suspension - some practical aspects, Proceedings of the IEEE International Conference on Mechatronics, ICM'04, June 35, Istanbul, Turkey, pp. 41-45.

Sammier, D., Sename, O. and Dugard, L. (2003) Skyhook and Hळ control for semi-active suspensions: some practical aspects, Vehicle System Dynamics, Vol. 39, No 4, pp. 279-308.

Williams, D. E. (1997) Active Suspension Control to Improve Vehicle Ride and Handling, Vehicle System Dynamics, Vol. 28, No 1, pp.1-24. 


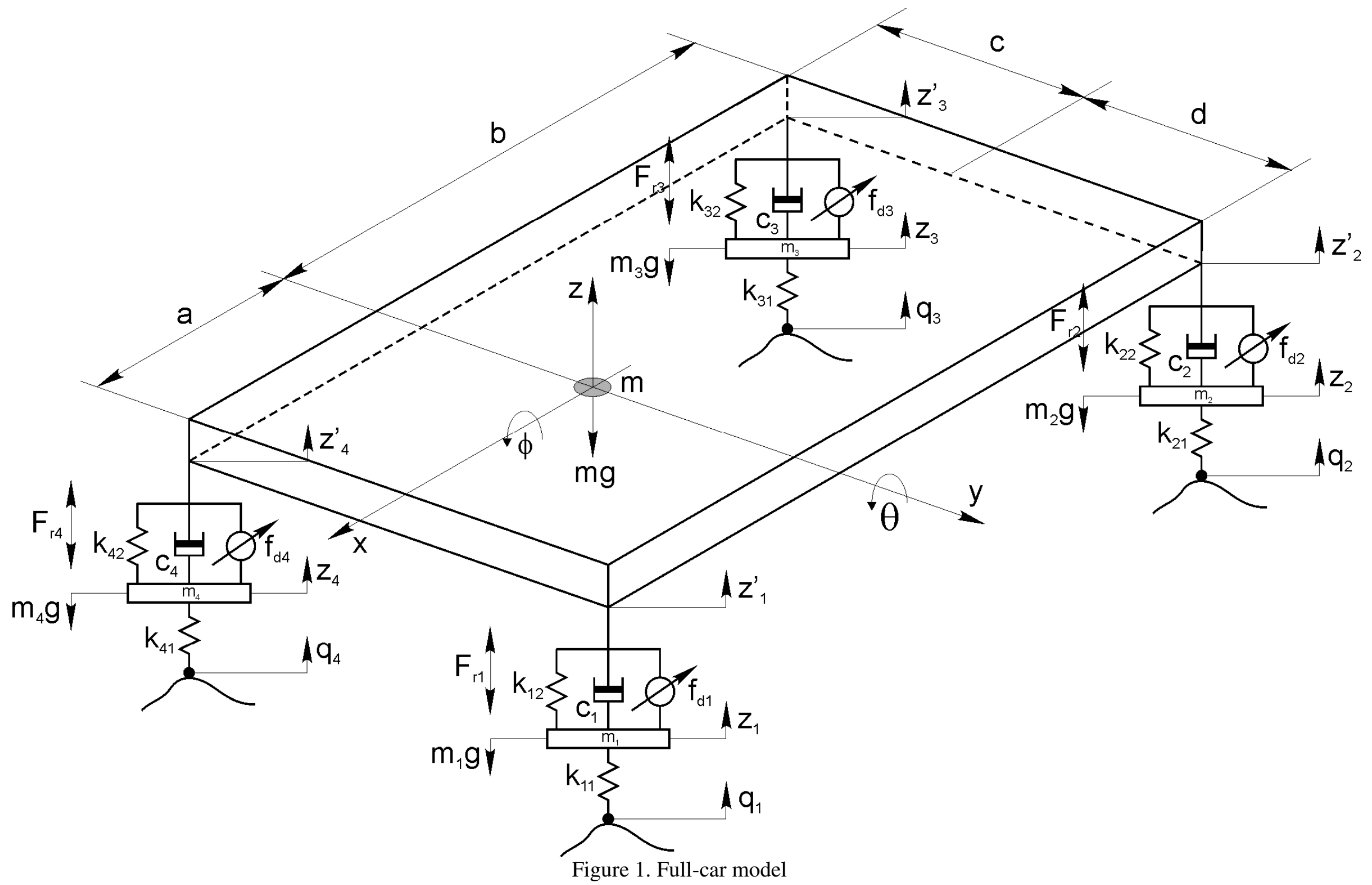




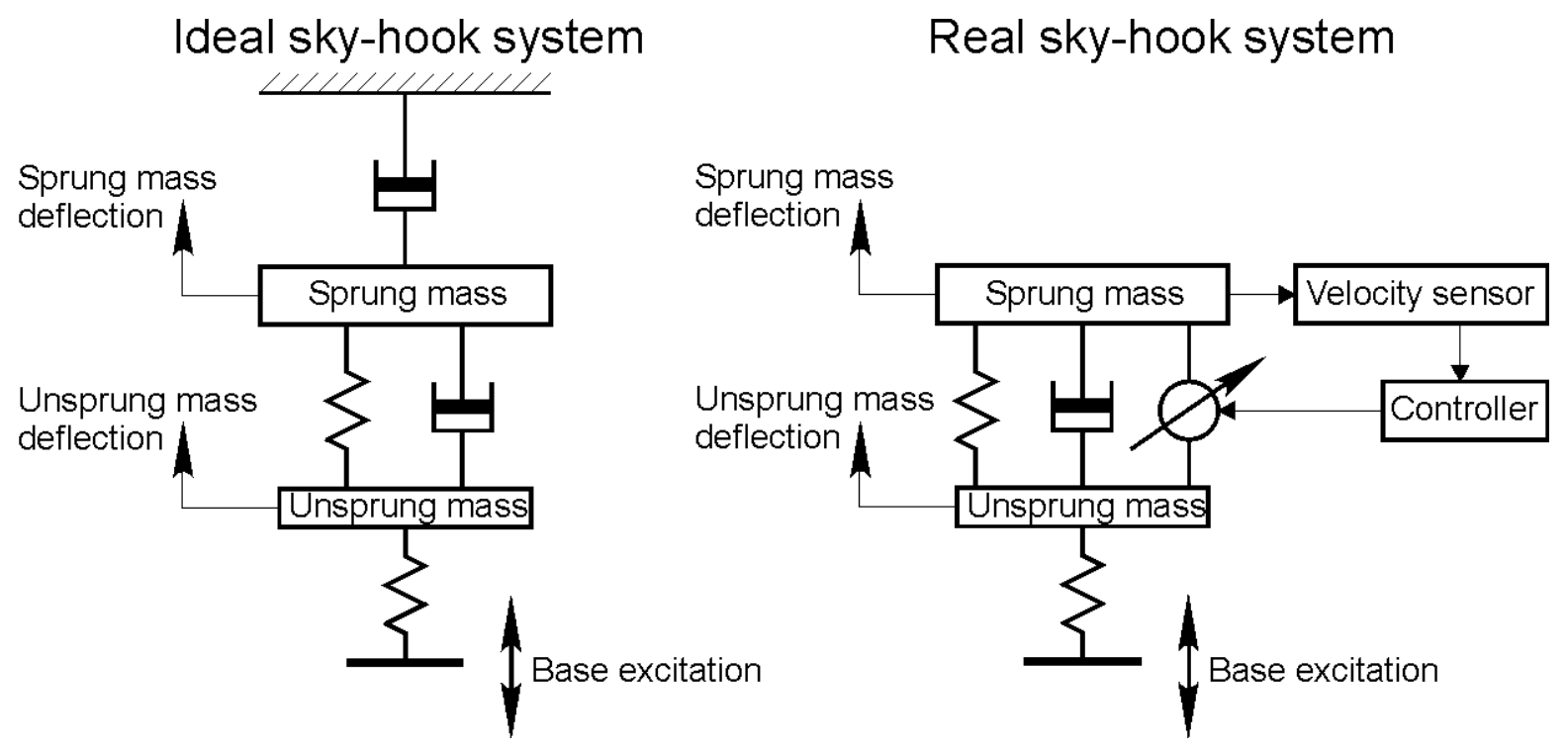

Figure 2. Skyhook damper concept

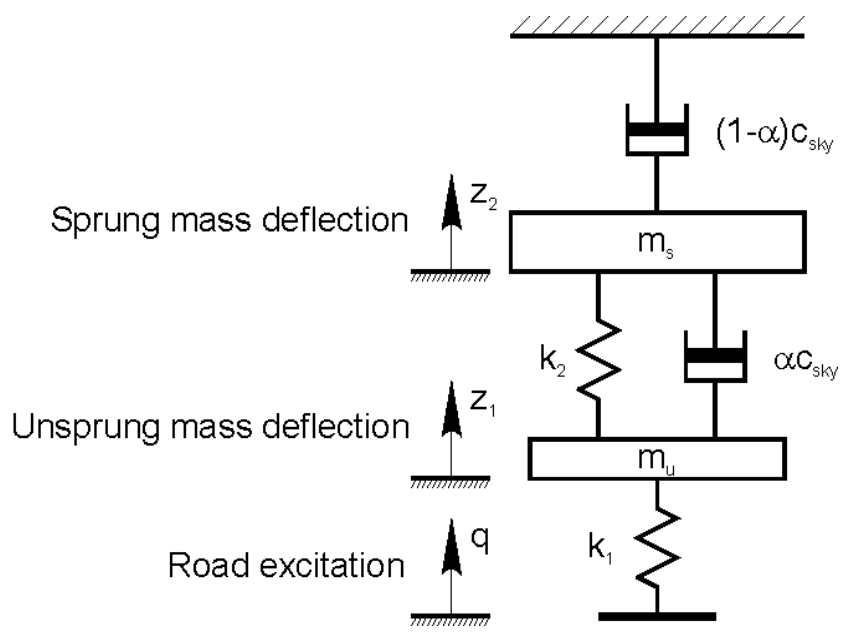

Figure 3. Skyhook suspension 


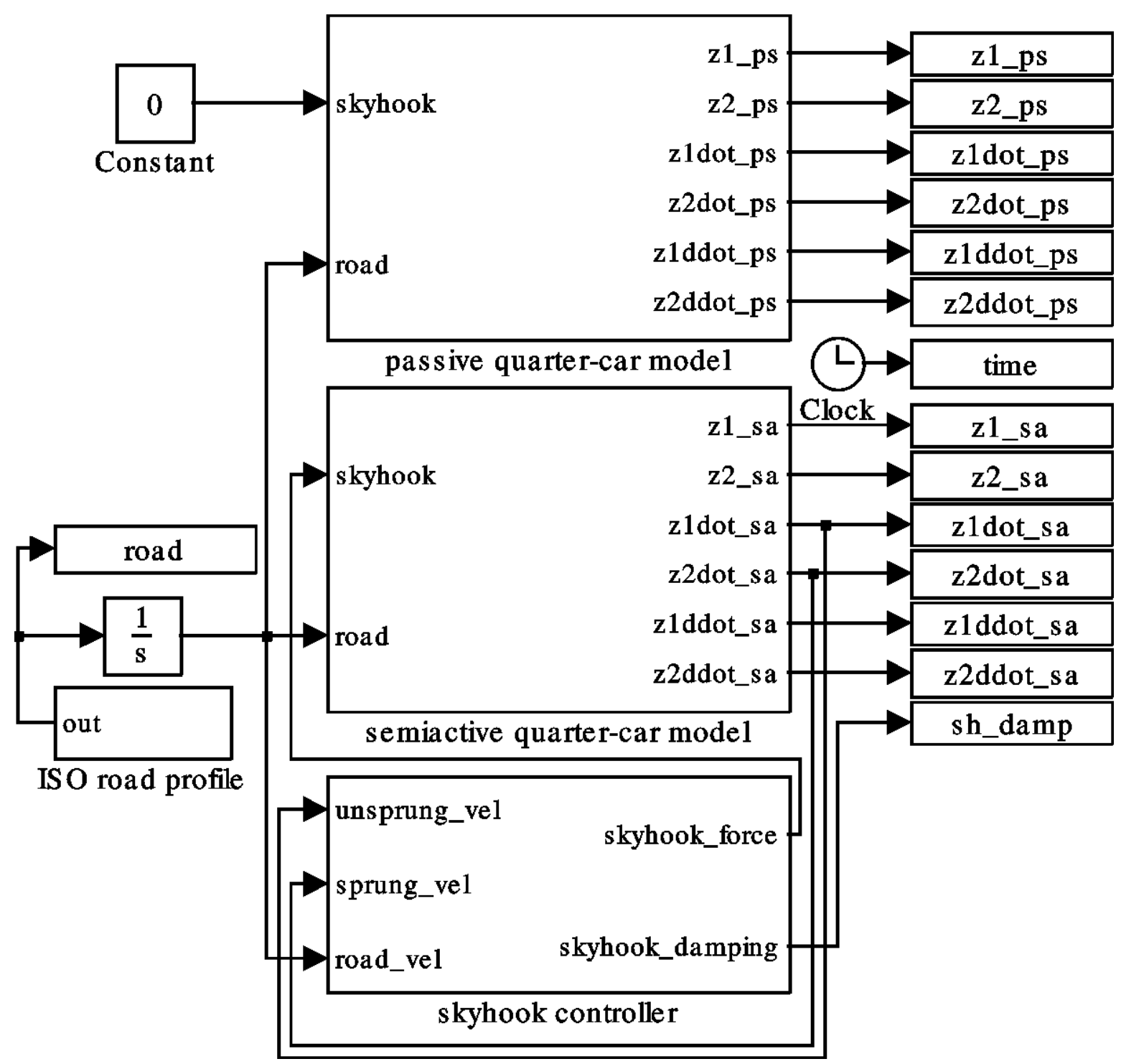

Figure 4. Quarter-car system with skyhook control 


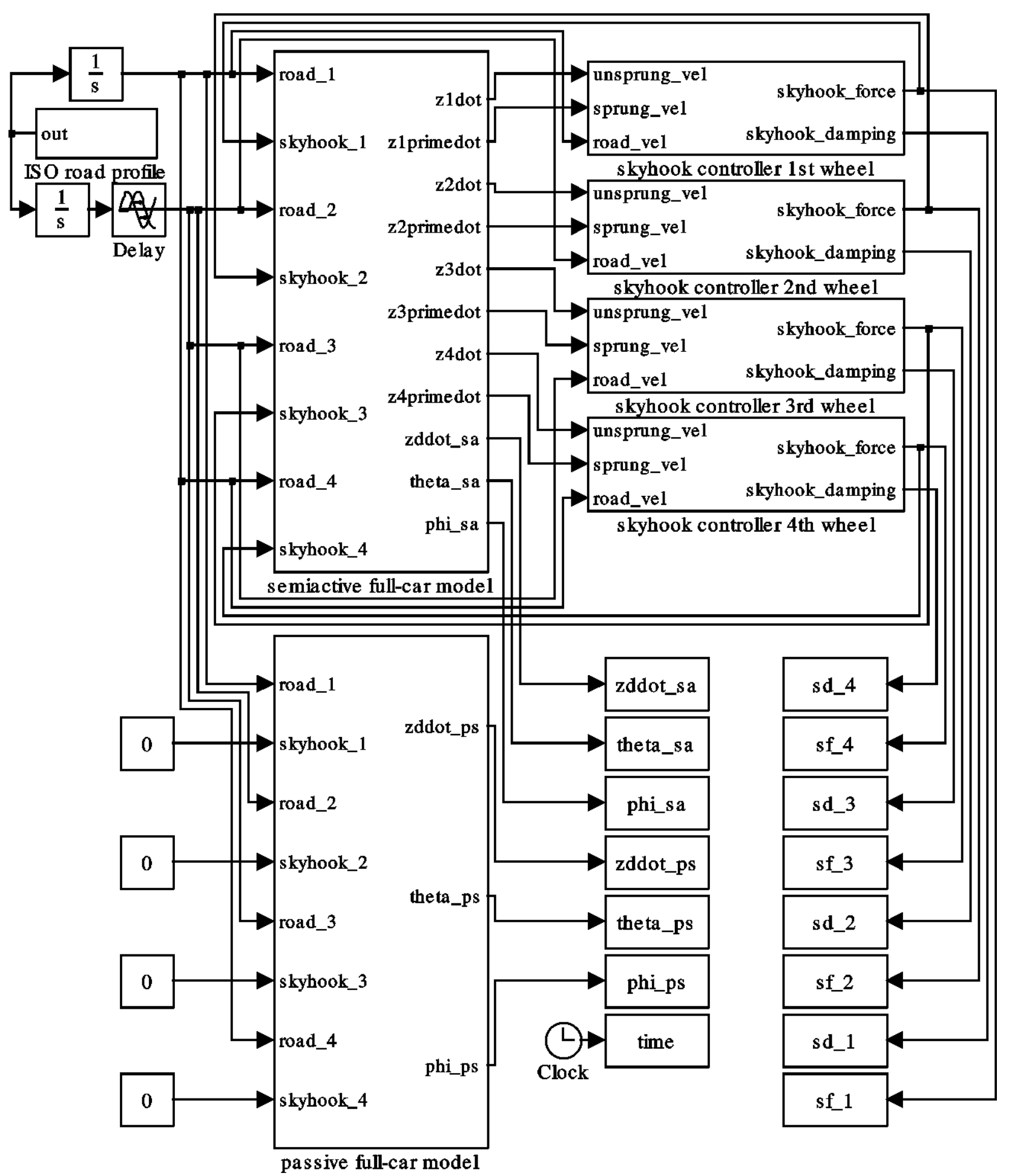

Figure 5. Full-car system with skyhook control 
Sprung mass bounce for the quarter-car (ISO class B)

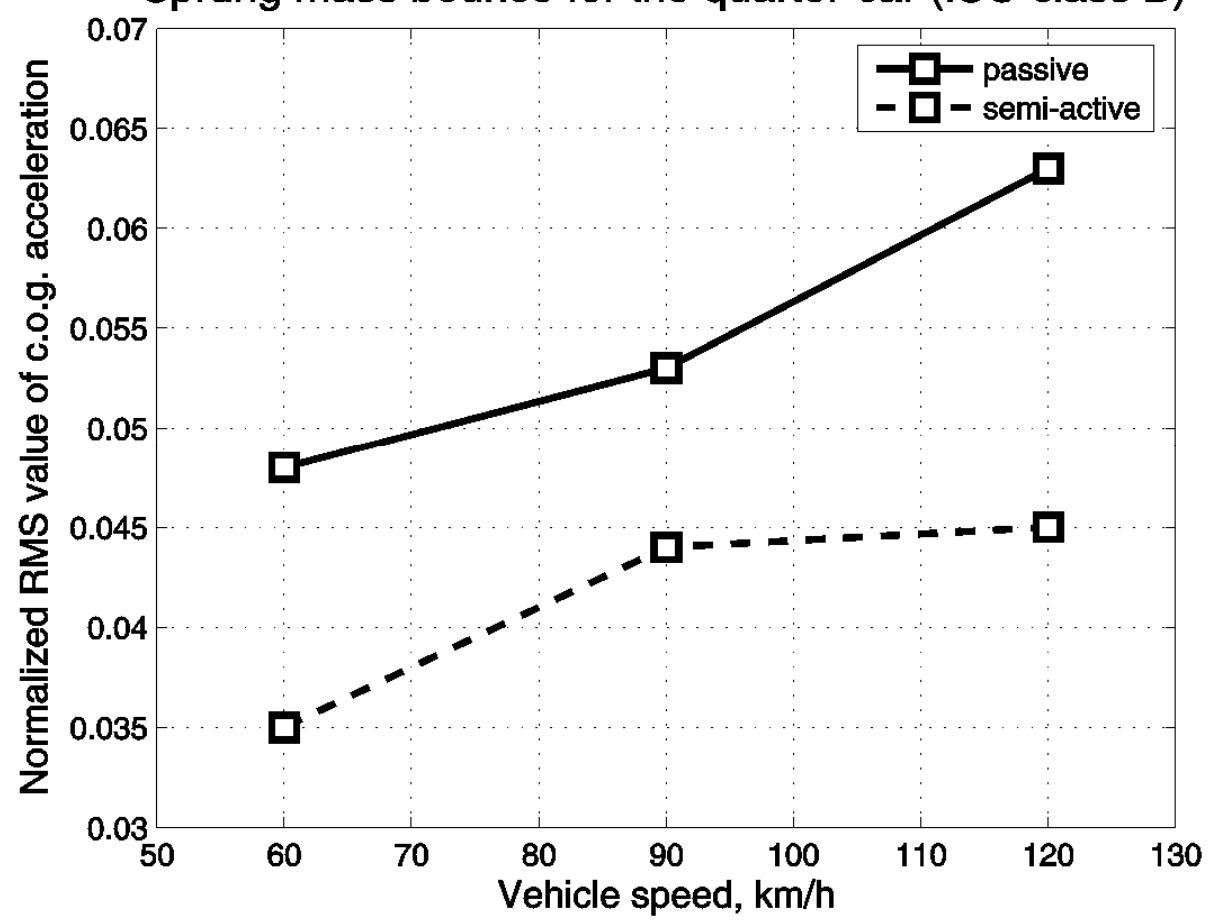

Sprung mass bounce for the full-car (ISO class B)

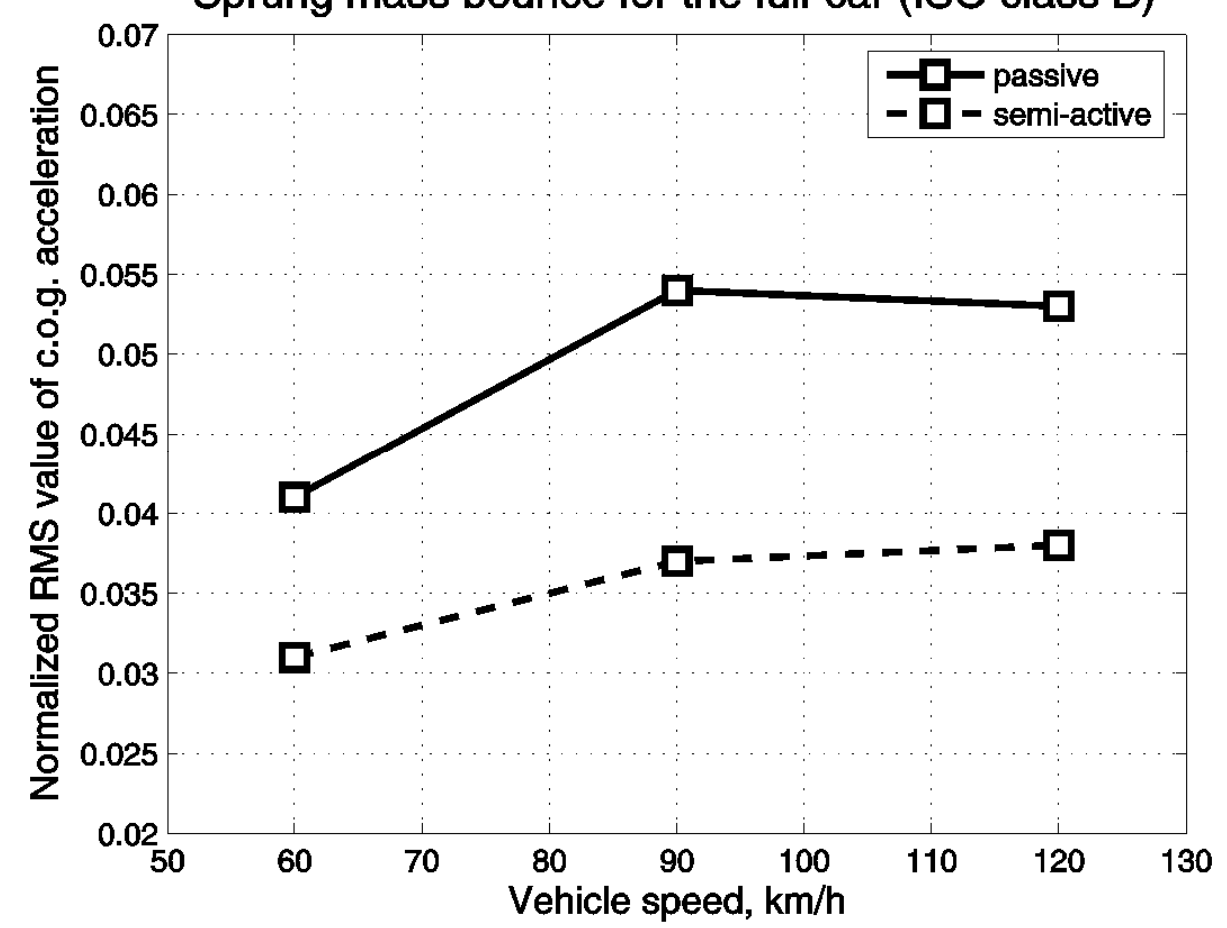

Figure 6. Normalized RMS values of sprung mass vertical acceleration for the quarter- and full-car models, travelling at different velocities (ISO class B) 

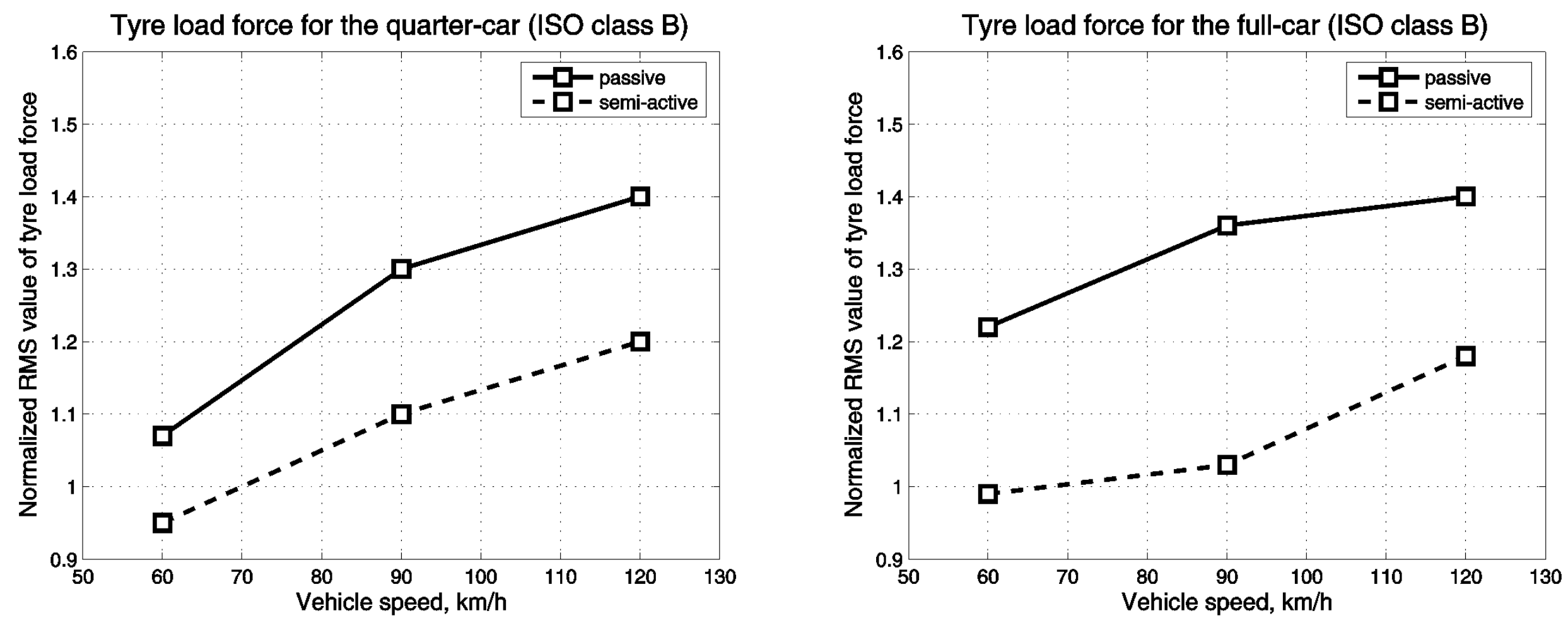

Figure 7. Normalized RMS values of tyre load force for the quarter- and full-car models, travelling at different velocities (ISO class B) 
Bounce acceleration of the c.o.g. for the quarter-car $(60 \mathrm{~km} / \mathrm{h})$

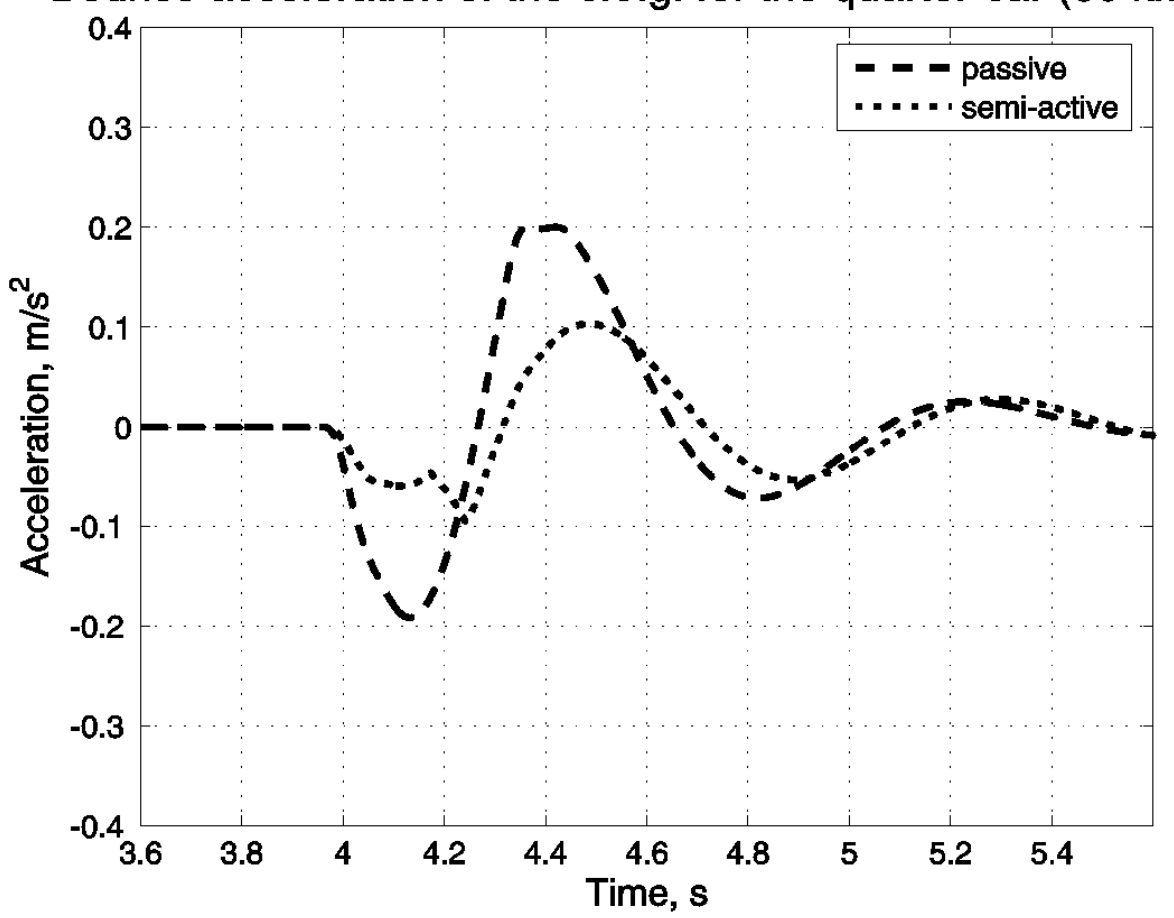

Bounce acceleration of the c.o.g. for the full-car $(60 \mathrm{~km} / \mathrm{h})$

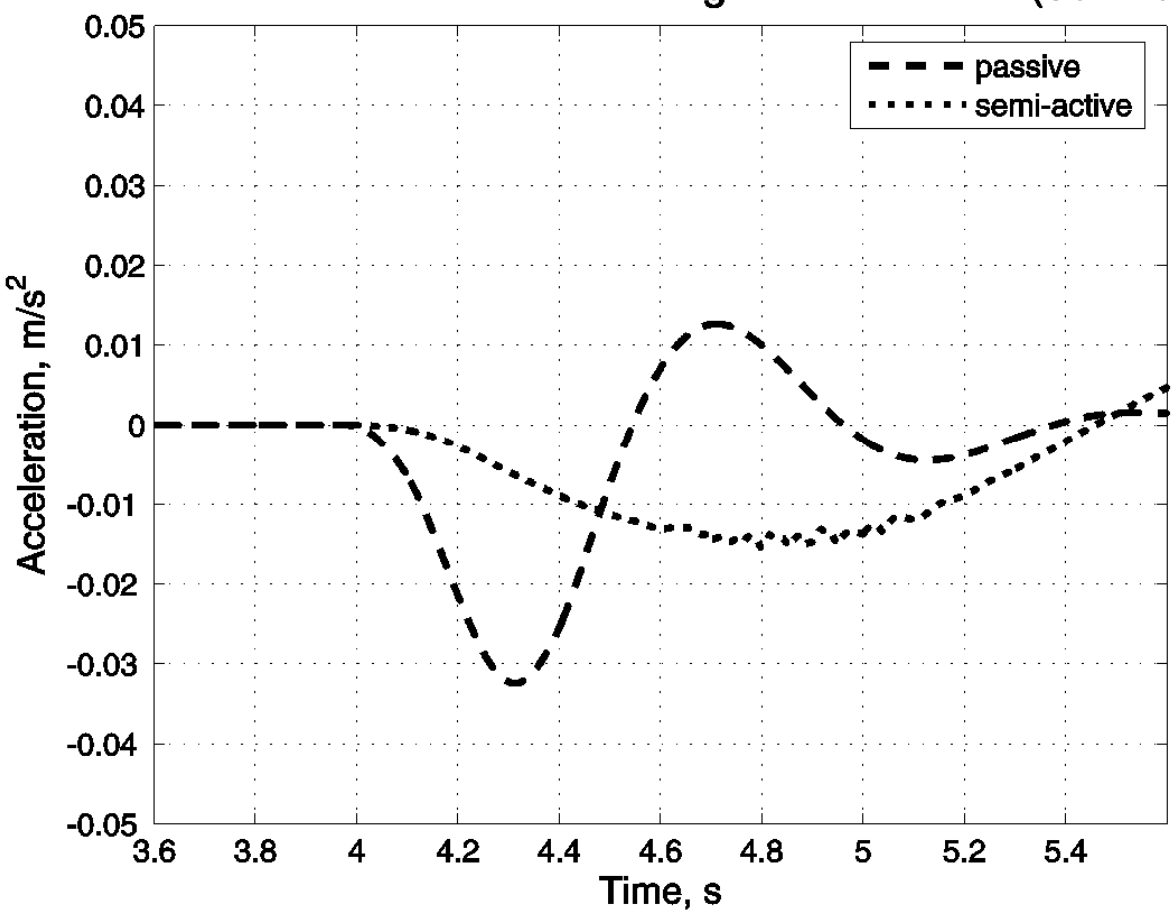

Figure 8. Quarter-and full-car models under sine wave hole test at $60 \mathrm{~km} / \mathrm{h}$ 
Bounce acceleration of the c.o.g. for the quarter-car $(90 \mathrm{~km} / \mathrm{h})$

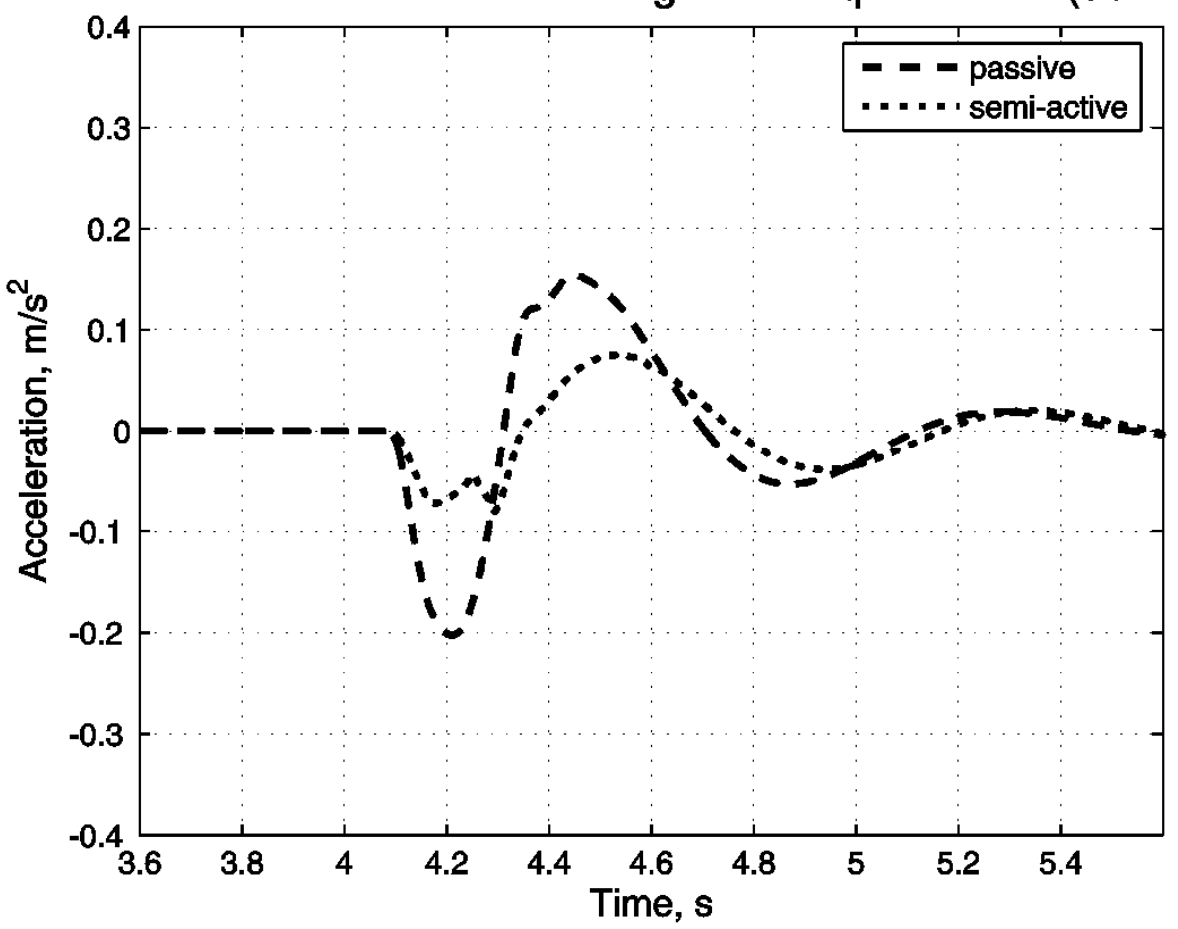

Bounce acceleration of the c.o.g. for the full-car $(90 \mathrm{~km} / \mathrm{h})$

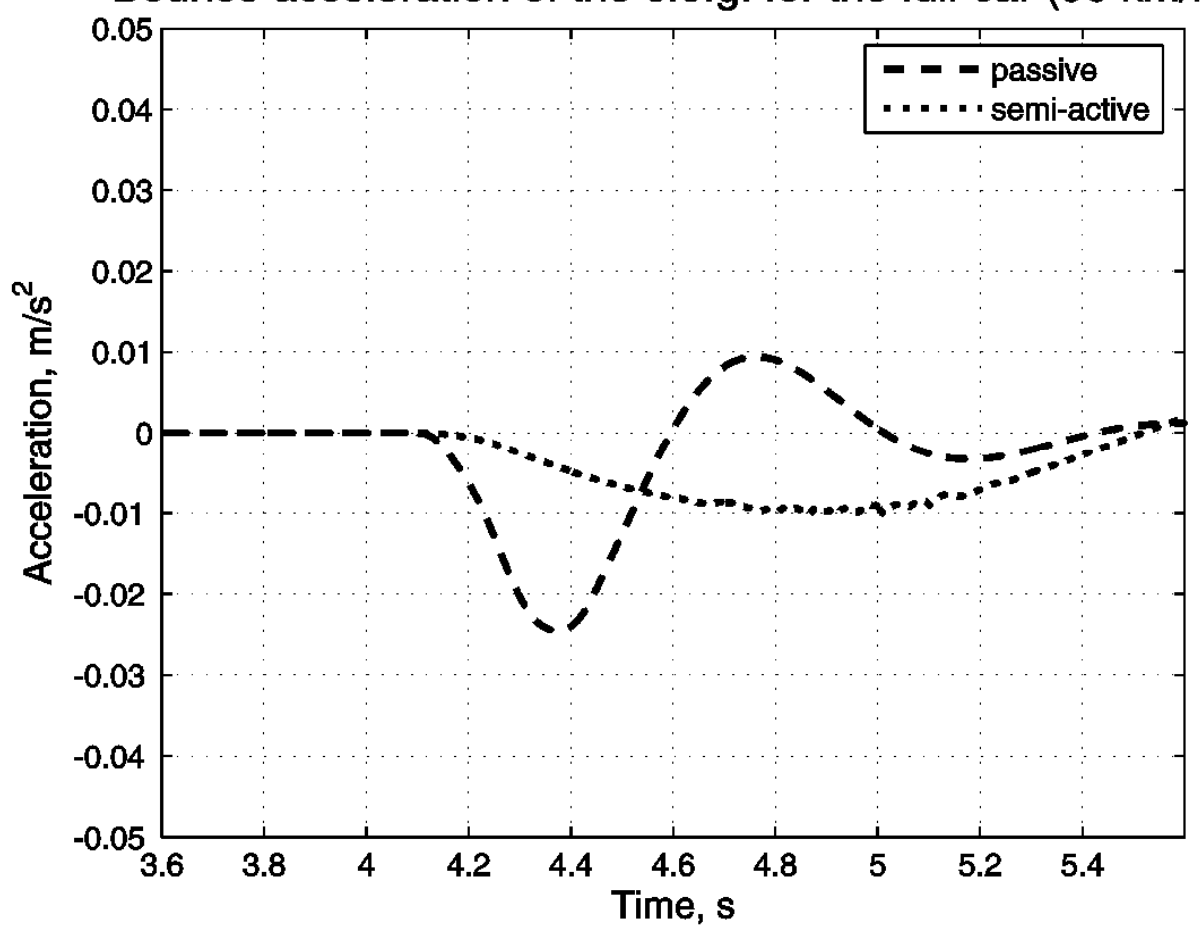

Figure 9. Quarter-and full-car models under sine wave hole test at $90 \mathrm{~km} / \mathrm{h}$ 

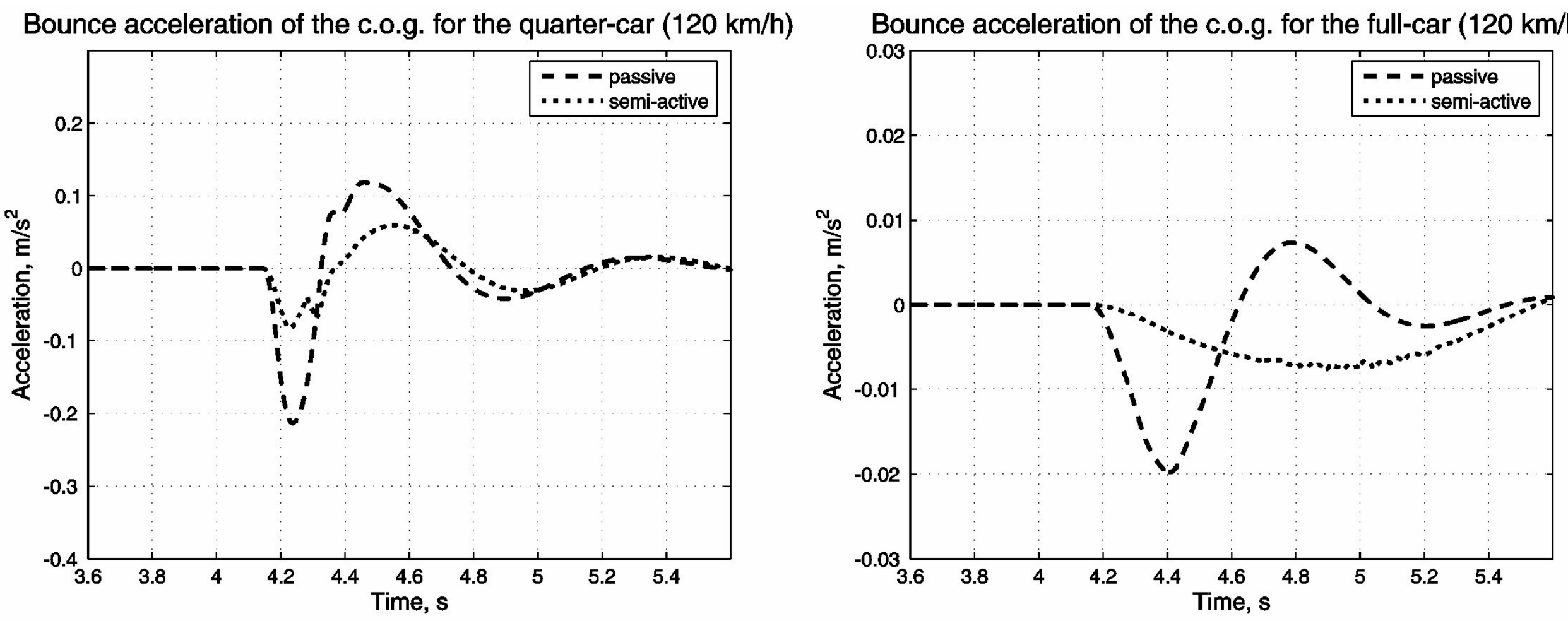

Figure 10. Quarter-and full-car models under sine wave hole test at $120 \mathrm{~km} / \mathrm{h}$ 

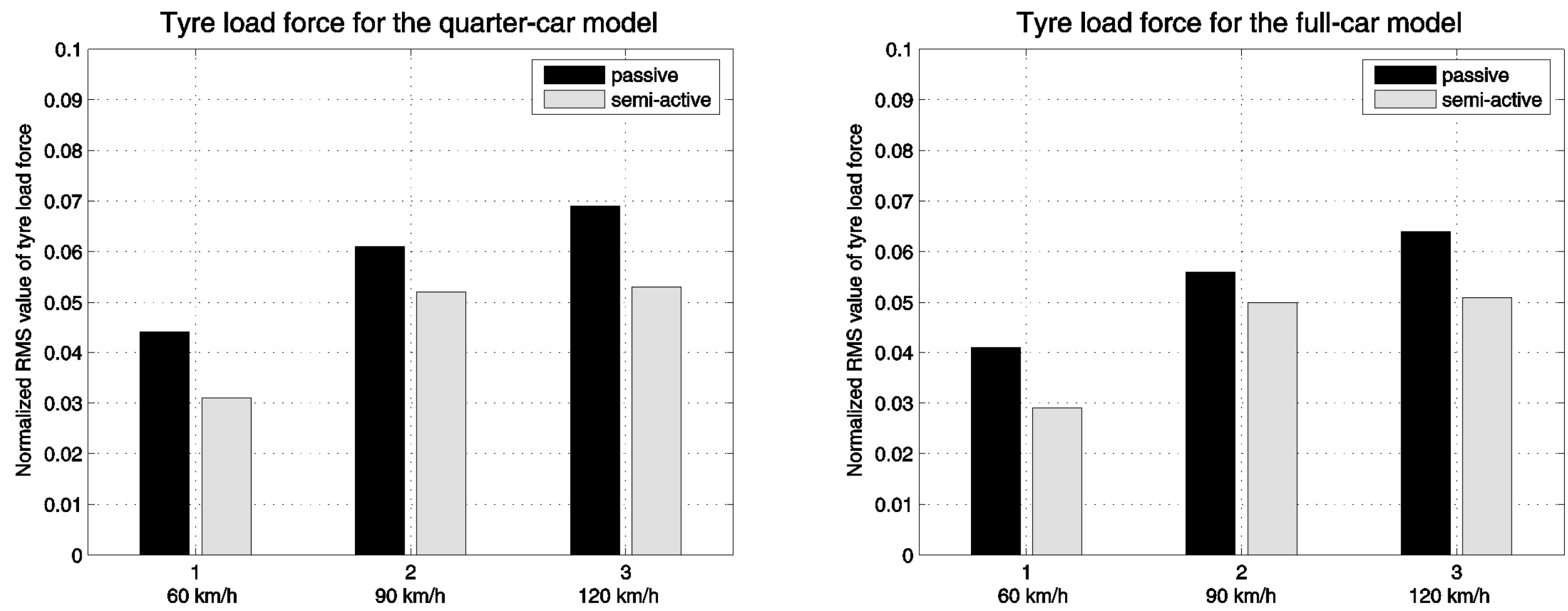

Figure 11. Tyre load force for the quarter- and full-car models under sine wave hole test 

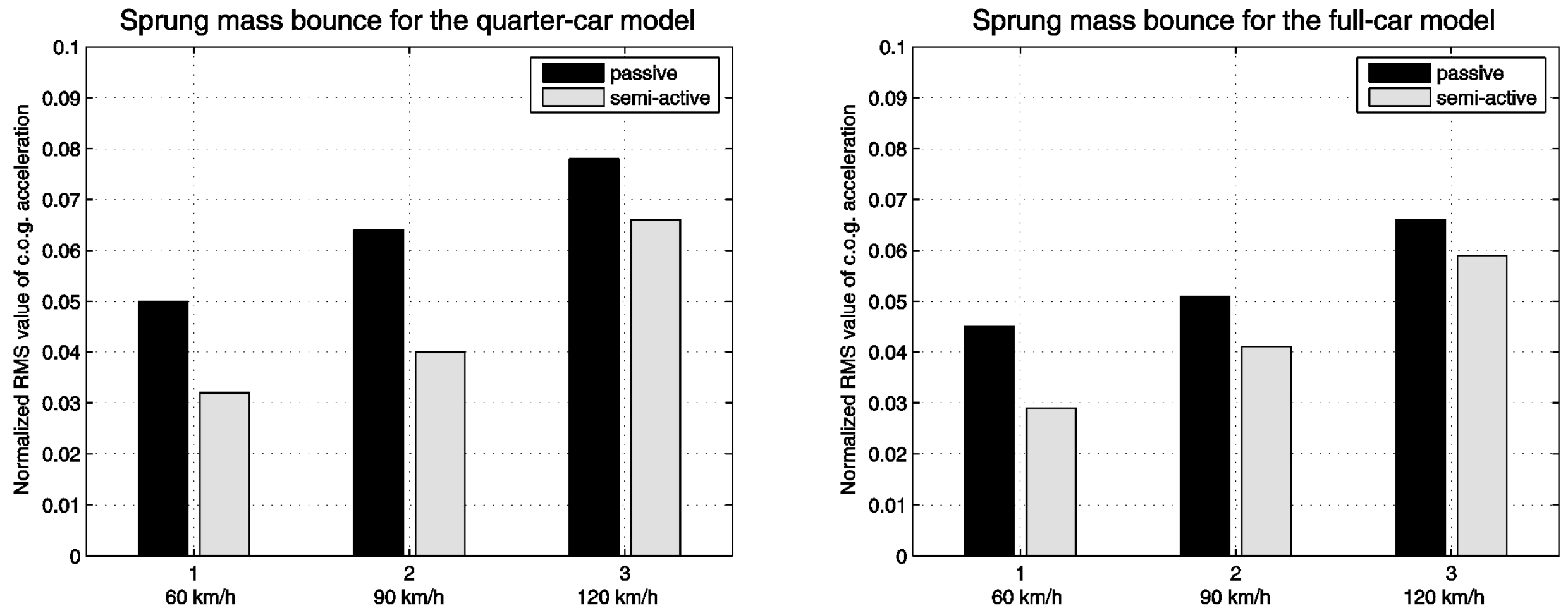

Figure 12. Quarter-car and full-car models under short back test 

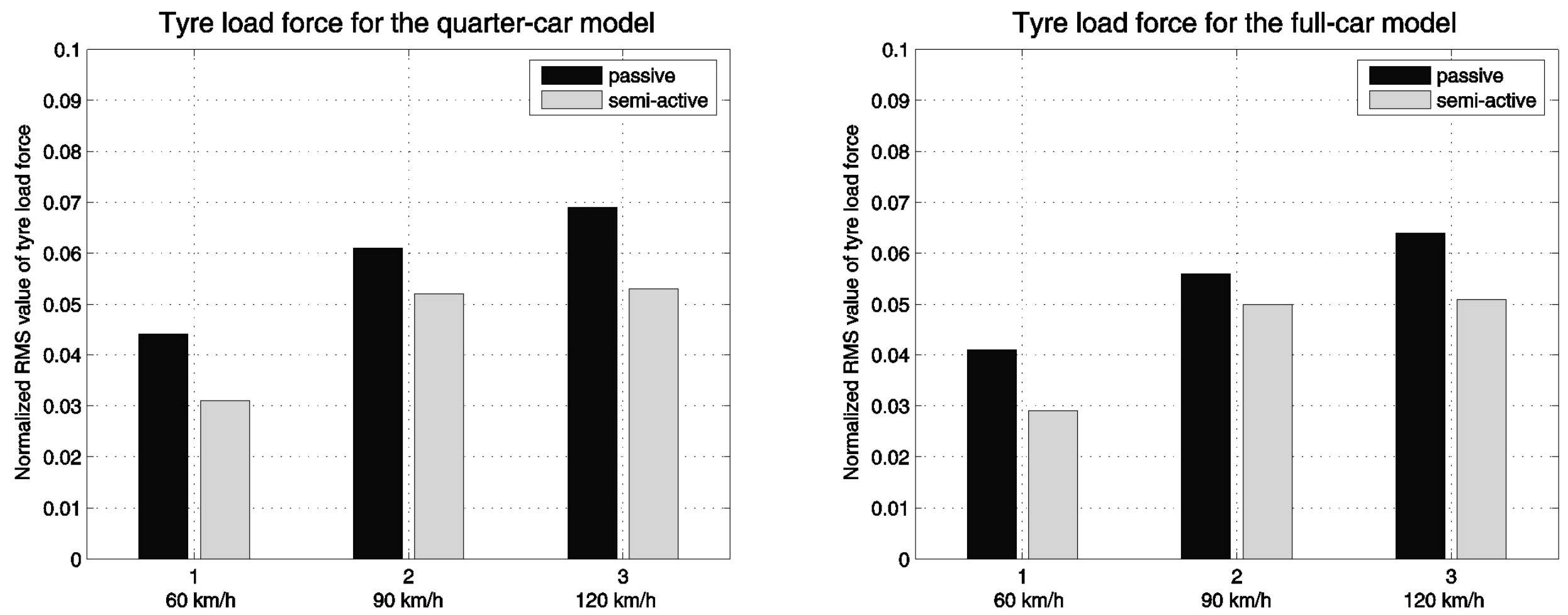

Figure 13. Tyre load force for the quarter- and full-car models under short back test 
Sprung mass bounce for the quarter-car model

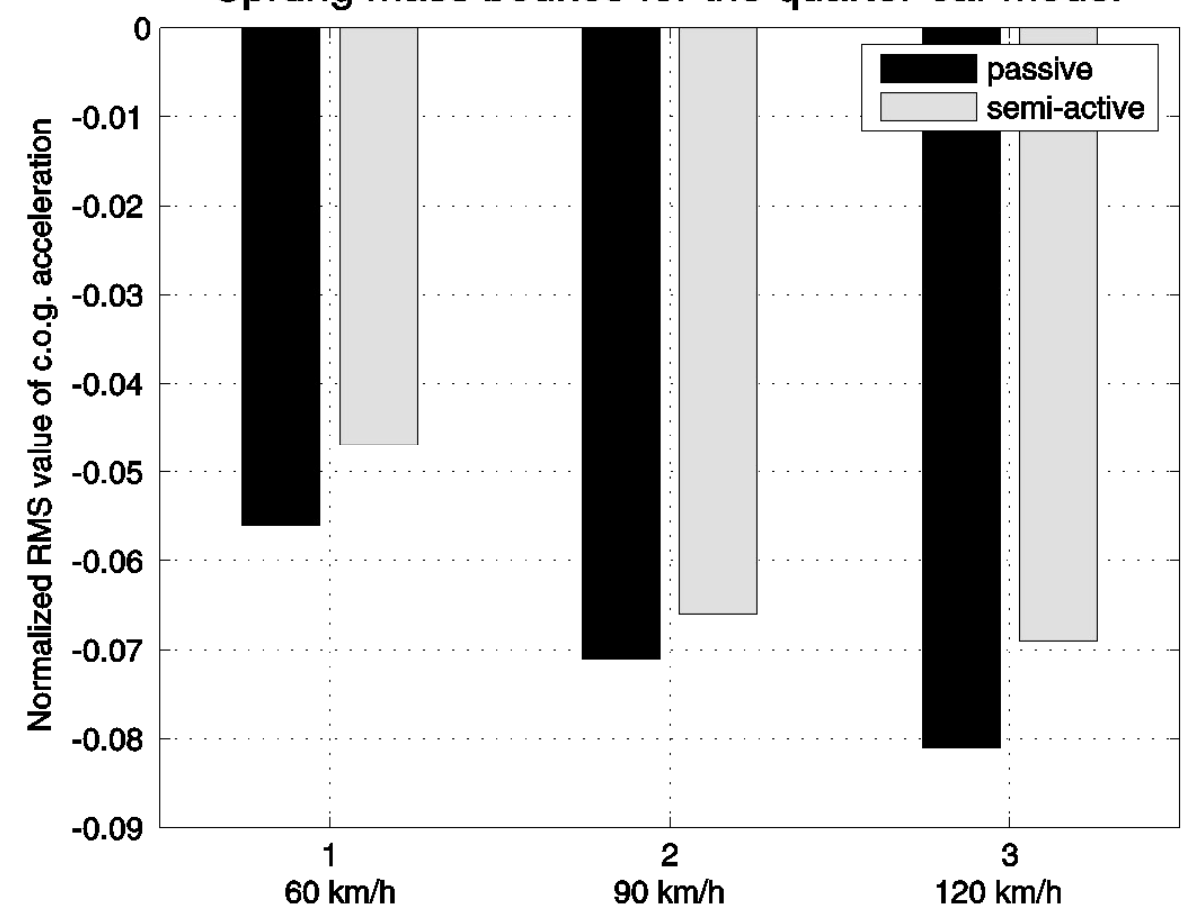

Sprung mass bounce for the full-car model

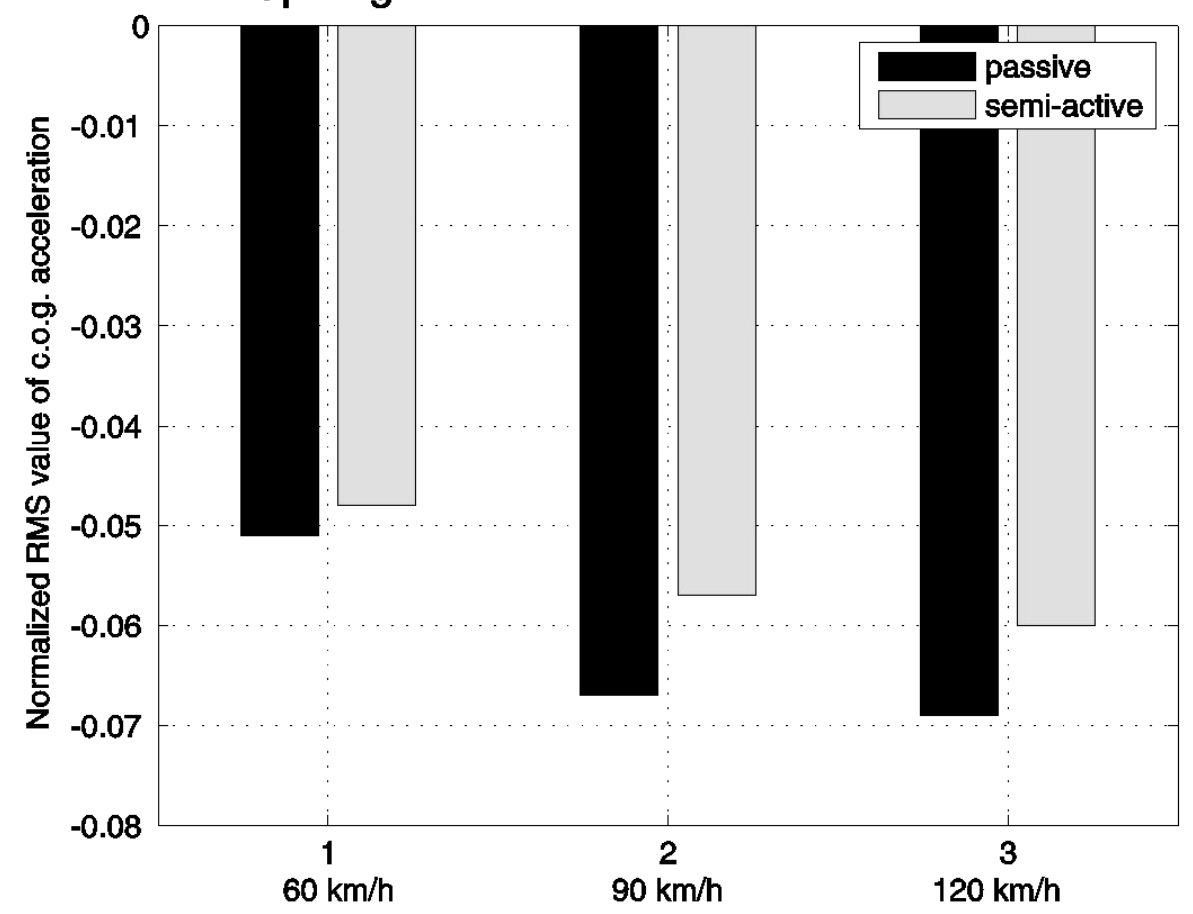

Figure 14. Quarter-car and full-car models under drain well test 

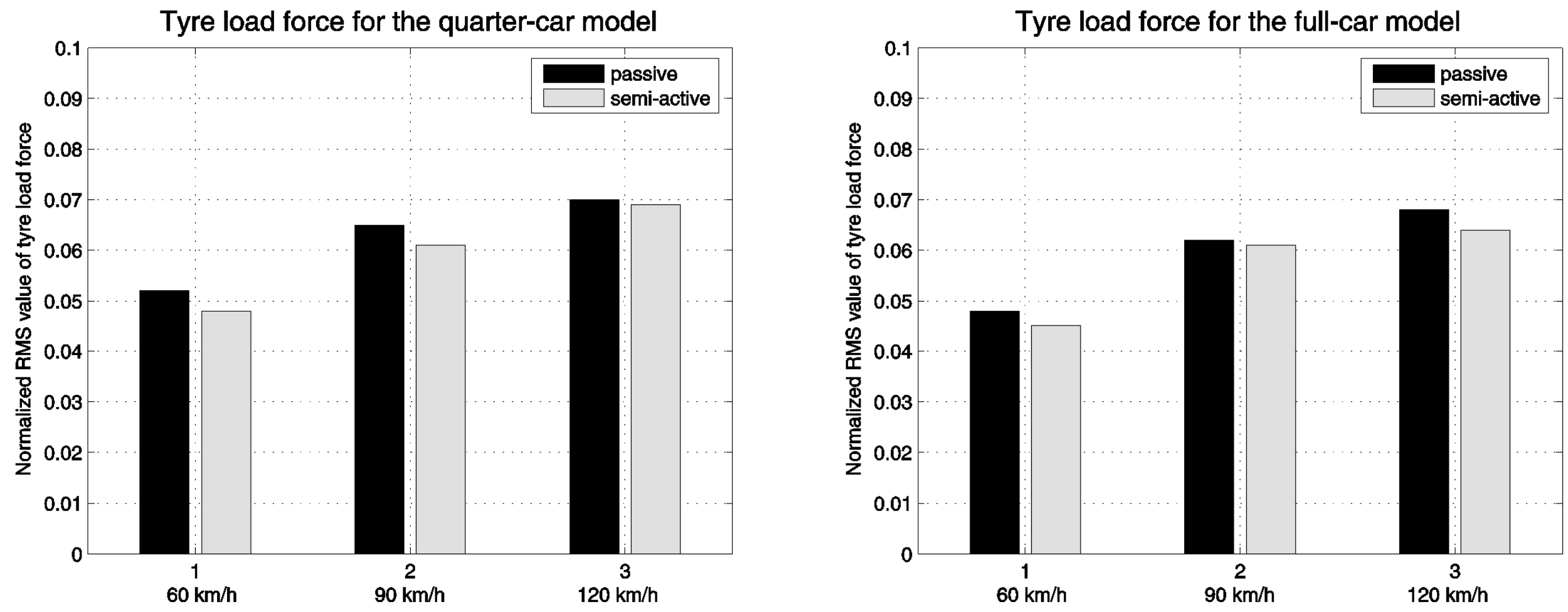

Figure 15. Tyre load force for the quarter- and full-car models under drain well test 
Sprung mass bounce for the quarter-car model

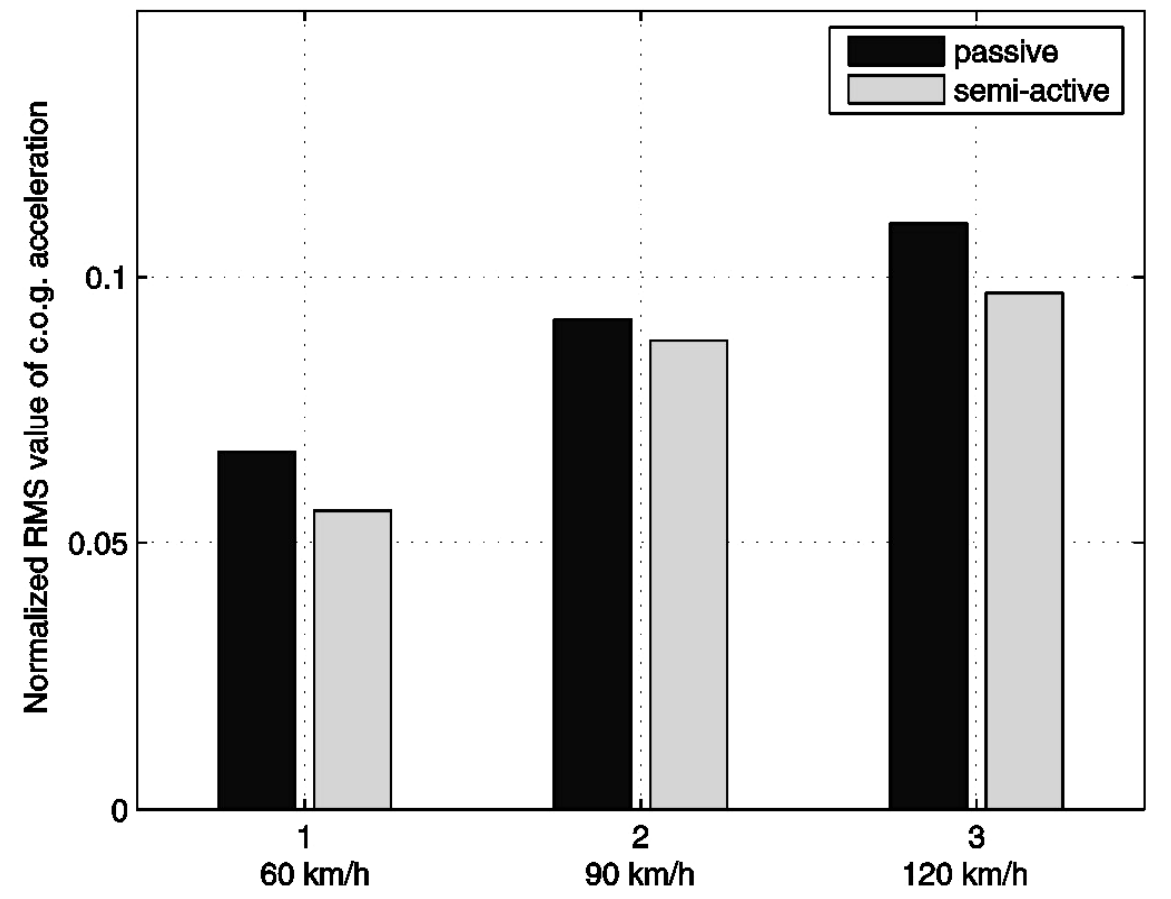

Sprung mass bounce for the full-car model

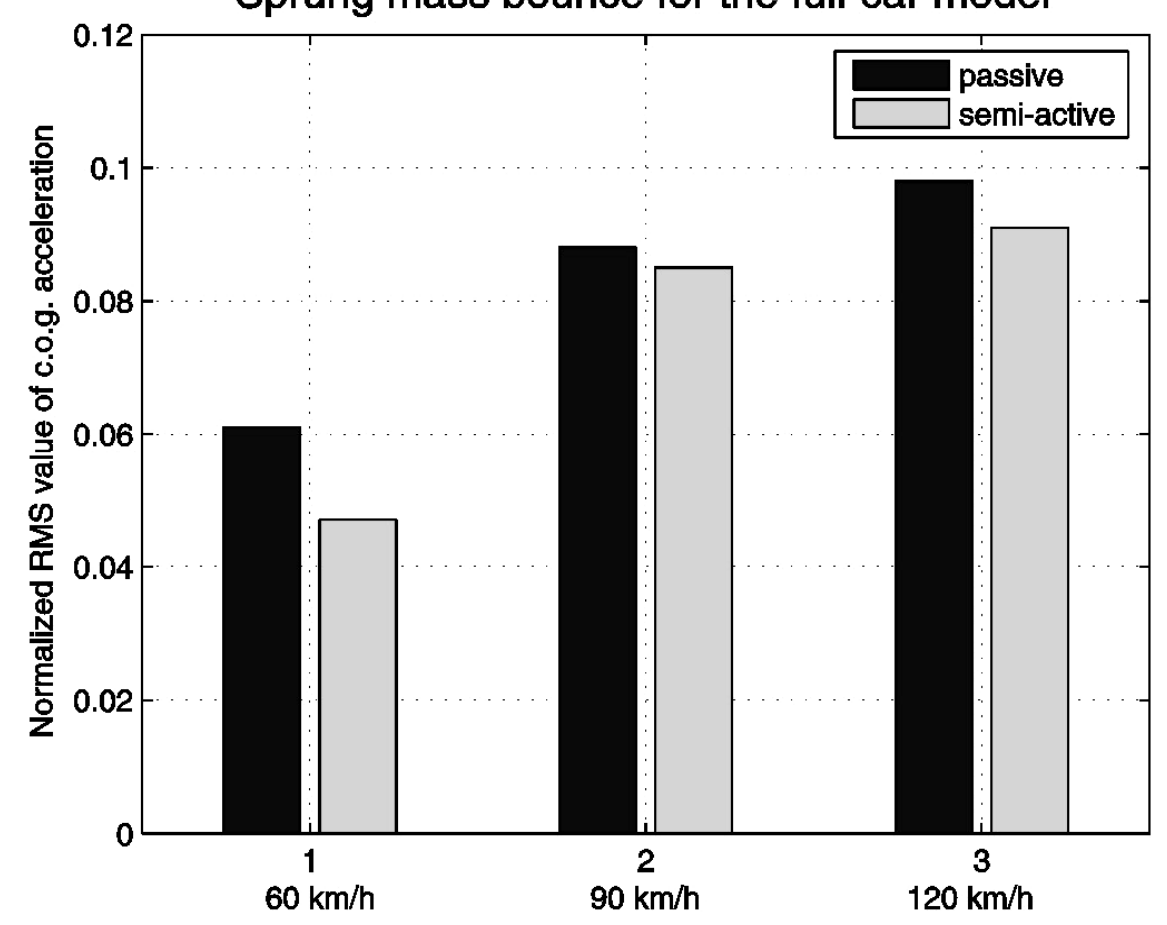

Figure 16. Quarter-car and full-car models under English track test 

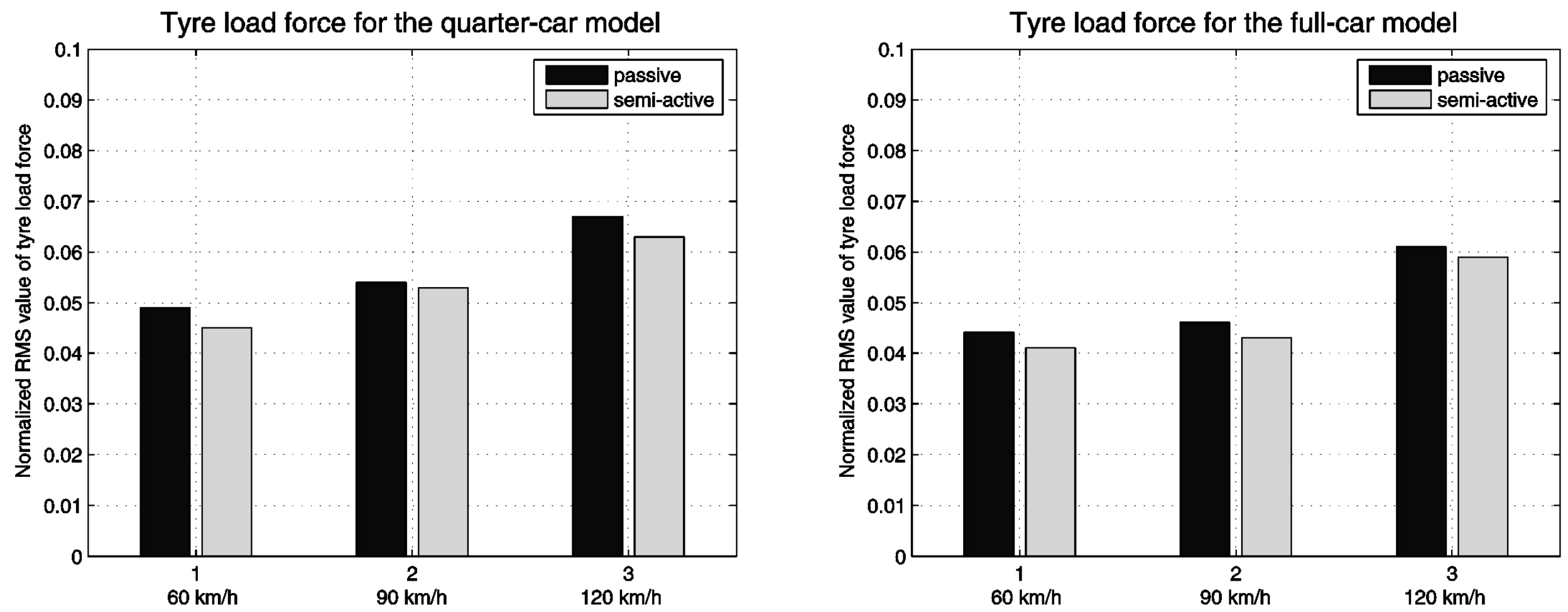

Figure 17. Tyre load force for the quarter- and full-car models under English track test 